\title{
O SIGNIFICADO PALEOAMBIENTAL DE PALINOMORFOS DE FUNGOS EM TURFAS QUATERNÁRIAS DO MÉDIO VALE DO RIO PARAÍBA DO SUL, SP, BRASIL
}

\author{
Raimundo Souza SILVA \\ Maria Judite GARCIA \\ Rudney de Almeida SANTOS \\ Paulo Eduardo DE OLIVEIRA \\ Paulo César Fonseca GIANNINI \\ Mary Elizabeth C. BERNARDES-DE-OLIVEIRA \\ Vanda Brito de MEDEIROS \\ Carlos Alberto BISTRICHI \\ Rosana Saraiva FERNANDES \\ Marco Felipe RACZKA
}

\begin{abstract}
RESUMO
O presente trabalho trata do estudo de esporos de fungos provenientes de um testemunho obtido numa das turfeiras do distrito de Eugênio de Melo, médio vale do rio Paraíba do Sul, estado de São Paulo, Brasil. Com idades entre 11.240 e 300 cal. anos AP, o testemunho mostrou dois ciclos sedimentares, separados por um hiato de cerca de 7.000 anos. A extração dos palinomorfos seguiu o protocolo de processamento de sedimentos quaternários, com dissolução dos silicatos e silicofluoretos, eliminação dos ácidos húmicos e acetólise. Identificaram-se 210 tipos de palinomorfos de fungos, baseado na comparação com gêneros e espécies fósseis afins e modernas, com a finalidade de estabelecer seu significado ecológico; destes, os 40 mais representativos foram selecionados para elaboração de diagramas, que permitiram estabelecer três intervalos. O Intervalo I entre as profundidades de 360 e $190 \mathrm{~cm}$ e idades entre $11.240 \mathrm{cal}$. anos AP e 8.930 anos AP (idade interpolada); o Intervalo II entre as profundidades de 191 e $110 \mathrm{~cm}$ e idades entre $>718$ e 550 anos AP (interpolada); e o Intervalo III entre as profundidades de 110 e $0 \mathrm{~cm}$ e idades entre 550 anos AP (interpolada) e atual. Constatou-se que os espécimes dominantes são os de hábito saprófito (decompositores de matéria orgânica em putrefação), seguidos pelos parasitas, especialmente de folhas e de animais (menos comum), além daqueles patógenos de vegetais e coprófitos. A assembleia de esporos de fungos ao longo do perfil sedimentar indica desenvolvimento e preservação em ambiente redutor, com farta disponibilidade de matéria orgânica. Alguns tipos de esporos micorrízicos evidenciam presença de vegetação rasteira (Cyperaceae e Poaceae) associada a locais úmidos e/ou alagados. A ocorrência de Ascodesmisites malayensis, saprófito de folhas mortas de Cyperaceae, encontrado nos sedimentos datados entre $11.240 \mathrm{cal}$. anos AP e 10.800 (idade interpolada), confirma substrato encharcado ou com nível de água mais elevado. Anatolinites, gênero patógeno hospedeiro em folhas de vegetais vivas, ocorre no início do intervalo II, após o hiato temporal $( \pm 7.000$ anos AP), quando a área deve ter sido retomada por matas. Parasitas de vegetais, como Diporicellaesporites $\mathrm{cf}$. D. liaoningensis e Diporicellaesporites sp. 9, habitam substratos lenhosos e indicam existência de vegetação arbórea no primeiro ciclo de deposição. Monoporisporites sp. 6, decompositor de excrementos, tem sido relacionado com esterco de animais herbívoros e ocorre nos últimos 300 anos. Sua abundância nesse intervalo provavelmente está relacionada à ação antrópica nas áreas hoje constituídas por turfeiras.
\end{abstract}

Palavras-chave: Palinologia; palinomorfos; esporos de fungos; turfeiras; Eugênio de Melo; Quaternário; Brasil. 


\section{ABSTRACT}

THE PALEOENVIRONMENTAL SIGNIFICANCE OF FUNGAL PALYNOMORPHS IN A QUATERNARY PEAT FROM THE MIDDLE PARAIIBA DO SUL RIVER VALLEY, SP, BRAZIL. This study deals with spores, conidia and hyphae of fungi present in a peatbog core from the Eugenio de Melo district, middle Paraíba do Sul River Valley in the State of São Paulo, Brazil. Dated between 11,240 to 300 cal. years BP, the core comprises parts of two sedimentary cycles separated by a hiatus of about 7,000 years. Palynomorphs were extracted following standard procedures with the dissolution of mineral components and elimination of humid acids, followed by acetolysis. A total of 210 fungal palynomorphs were identified based on comparison with fossil and modern genera and species with the aim of determining their paleocological significance; diagrams were prepared of 40 palynomorphs selected as representative of the diversity of the assemblage which allowed three intervals to be estalished: Interval I between 360 and $190 \mathrm{~cm}$ depths with ages between 11,240 cal. yr BP and 8,930 years BP (interpolated age); Interval II between 191 and $110 \mathrm{~cm}$ depths and $>718$ and 550 years $\mathrm{BP}$ (interpolated) in age; and interval III between 110 and $0 \mathrm{~cm}$ depths dated between 550 years BP (interpolated) and the present. The majority of the taxa found in this study are saprophytes, followed by leaf parasites as well as pathogens and fecal decomposers. The fungal spore assemblages along the sediment profile indicate growth and preservation within a reducing environment containing abundant decaying organic matter. Some mycorrhizal spores are associated with Cyperaceae/Poaceae in wet environments and/or with Poaceae in waterlogged conditions, which is indicative of open vegetation in both cases. The occurrence of Ascodesmisites malayensis, a saprophyte on Cyperaceae leaves, in sediments dated from 11,240 cal. years BP and 10,800 years BP (interpolated age) confirms a soaked substrate or highest levels of water. Anatolinites, a pathogenic genus thriving on leaves of living plants, occurs at the beginning of interval II, after a hiatus of about 7,000 years BP, when the area was covered by forests. Plant parasites of woody substrates, such as Diporicellaesporites cf. D. liaoningensis and Diporicellaesporites sp. 9, indicate prevailing arboreal vegetation during the first cycle of organic matter deposition. The abundance of Monoporisporites sp. 6, a fecal decomposer, which has been related to the presence of herbivorous animals within the last 300 years, is likely related to anthropogenic activities in the modern peatbogs.

Keywords: Palynology; palynomorphs; fungal spores; Eugênio de Melo; Quaternary; Brazil.

\section{INTRODUÇÃO}

Os palinomorfos de fungos praticamente não sofrem transporte, representam o local de deposição, especialmente quando a concentração relativa de outros palinomorfos é baixa, e, por isso, tem sido importantes nas reconstruções paleoambientais e paleoecológicas.

POPOV (1967) desenvolveu os primeiros estudos sobre esses palinomorfos, entre os quais, descreveu diversos tipos de esporos atribuídos a fungos parasitas patógenos associados a diferentes partes dos vegetais (caules, folhas etc.). Assim, por exemplo, espécies de Puccinia e Helminthosporium predominam nas poáceas, Camparosporonium nas folhas de acácias e efedras e Hendersonia, nas folhas das rosáceas e tifáceas.
Estudos mais recentes, baseados na paleomicota e coprofagia, têm auxiliado em reconstruções paleoambientais e permitido detectar alterações paleovegetacionais climáticas em ecossistemas africanos (VAN GEEL et al. 2011a, b; GELORINI et al. 2011). De acordo com PEIXOTO JÚNIOR (2011) e TEIXEIRA-SANTOS et al. (2015), grãos de pólen de poáceas associados aos de plantas vasculares coincidem com a presença significativa de esporos de fungos parasitas patógenos, que produzem a ferrugem marrom sobre os vegetais, como por exemplo Puccinia, que se desenvolve em poáceas silvestres e cultivadas, além de outros (Helminthosporium e Mycosphaerella).

$\mathrm{Na}$ arqueologia, FREITAS et al. (2015) mostraram que fungos patógenos como Curvularia, 
Alternaria, Puccinia e cf. Ustilago maydis, relacionados a grãos de pólen de mandioca, milho, algodão, palmeiras e árvores frutíferas, são sugestivos de atividades agrícolas de subsistência. O estudo desses fungos foi de grande importância no conhecimento dos primeiros traços culturais das cidades de cerâmicas antigas da Serra de Baturité (Ceará, Brasil).

O conhecimento da ecologia dos fungos fósseis, conforme apresentado, permite as reconstruções paleoambientais, paleoclimáticas e arqueológicas. Desde a década de 60 os fungos fósseis também são usados em bioestratigrafia, envolvendo estudos detalhados de caráter morfológico e sistemático.

ELSIK (1968) foi um dos pioneiros nos estudos de palinomorfos de fungos extraídos de sedimentos e estabeleceu um sistema de classificação artificial, com base na morfologia dos esporos, levando em conta as aberturas, forma, ornamentação, simetria e presença de septos. Tais características foram aplicadas em reconstruções paleoambientais e na palinoestratigrafia do Cenozoico (WOLF 1967a, b; ELSIK 1971, 1976a, b; ELSIK et al. 1983), bem como na indústria do petróleo (KALGUTKAR \& SIGLER 1995).

Desde então, diversos pesquisadores passaram a utilizar esses palinomorfos fósseis em interpretações paleoambientais: SHEFFY \& DILCHER (1971), PIROZYNSKI (1976a, b, c), RAMANUJAM \& RAO (1978), VAN GEEL (1978), RAMANUJAM \& SRISAILAM (1980), VAN GEEL et al. (1980), EDIGER (1981), JARZEN \& ELSIK (1986), PIROZYNSKI et al. (1988), ESHET et al. (1995), TAYLOR \& OSBORN (1996), KALGUTKAR (1997), KALGUTKAR \& JANSONIUS (2000), JANSONIUS \& KALGUTKAR (2000) e SONG \& HUANG (2002).

O presente trabalho apresenta a paleoecologia de palinomorfos de fungos de uma turfeira da várzea do rio Paraíba do Sul (Distrito de Eugênio de Melo, município de São José dos Campos/ SP), a partir de sua identificação, quantificação e comparação com outros previamente descritos em depósitos do Paleógeno, Neógeno e Quaternário (LORSCHEITTER 1984, GARCIA 1994, CARVALHO 1996, MEDEANIC et al. 2004, FERREIRA et al. 2005, LEAL \& LORSCHEITTER 2006, FREITAS \& CARVALHO 2011, entre outros). O estudo paleomicótico foi efetuado com as mesmas lâminas estudadas por SANTOS (2009) para palinologia. Dessa forma, os resultados e interpretações paleoclimáticas de ambos os estudos foram aqui comparados.

\section{2 ÁREA DE ESTUDO}

A extensa planície quaternária do médio vale do rio Paraíba do Sul, com aproximadamente $150 \mathrm{~km}$ de extensão por cerca de $5 \mathrm{~km}$ de largura, desenvolve-se a partir da região de Jacareí até a cidade de Lavrinhas, estado de São Paulo. É composta por aluviões, depositados sobre os sedimentos paleógenos e neógenos da Bacia Sedimentar de Taubaté que, por sua vez, se encontra sobre o embasamento cristalino Pré-Cambriano do leste paulista, no bloco tectônico Paraíba do Sul (HASUI et al. 1978).

Os aluviões do rio Paraíba do Sul apresentam, desde Jacareí até Pindamonhangaba, características distintivas (redução na granulometria dos corpos arenosos e na sua espessura, variação na largura da planície de inundação e do cinturão meândrico) que permitem, segundo MONTANHEIRO (2009), dividir a planície nos compartimentos Jacareí, Eugênio de Melo, Quiririm e Roseira. Tais compartimentos coincidem com aqueles propostos para as sub-bacias de Taubaté por HASUI et al. (1978) e MARQUES (1990).

A turfeira testemunhada encontra-se no compartimento Eugênio de Melo, à margem direita do rio Paraíba do Sul, no distrito homônimo, município de São José dos Campos, estado de São Paulo (Figura 1). Está situada na altitude aproximada de $600 \mathrm{~m}$ e nas coordenadas $45^{\circ} 50^{\prime} 38^{\prime \prime} \mathrm{W}$ e $23^{\circ} 07.57^{\prime} 36^{\prime \prime} \mathrm{S}$.

Segundo MONTANHEIRO (2009), no compartimento Eugênio de Melo a planície aluvial apresenta $6 \mathrm{~km}$ de largura por 22,3 km de extensão, entre São José dos Campos e Caçapava. O cinturão meândrico apresenta, aproximadamente, $1,5 \mathrm{~km}$ e os meandros abandonados mostram certa similaridade na morfologia e sinuosidade em relação aos atuais.

Os depósitos orgânicos que formam as turfeiras encontram-se sobre os sedimentos paleógenos e neógenos e sobre os depósitos de canais do cinturão meândrico subatual (VERDADE \& HUNGRIA 1966, GARCIA 1994). Os pacotes mais espessos estão entre São José dos Campos e Caçapava, na margem direita do rio, nas proximidades de Eugênio de Melo, com cerca de $11 \mathrm{~m}$ de espessura (MONTANHEIRO 2009).

Os depósitos orgânicos nas proximidades da faixa meândrica são recobertos por depósitos arenosos e argilosos, fruto do meandramento do rio. Conforme observado no presente trabalho, ocorre um mais antigo na base e, outro, bem mais recente, no topo.

Segundo VERDADE \& HUNGRIA (1966) e MONTANHEIRO (2009) o cinturão meândrico 

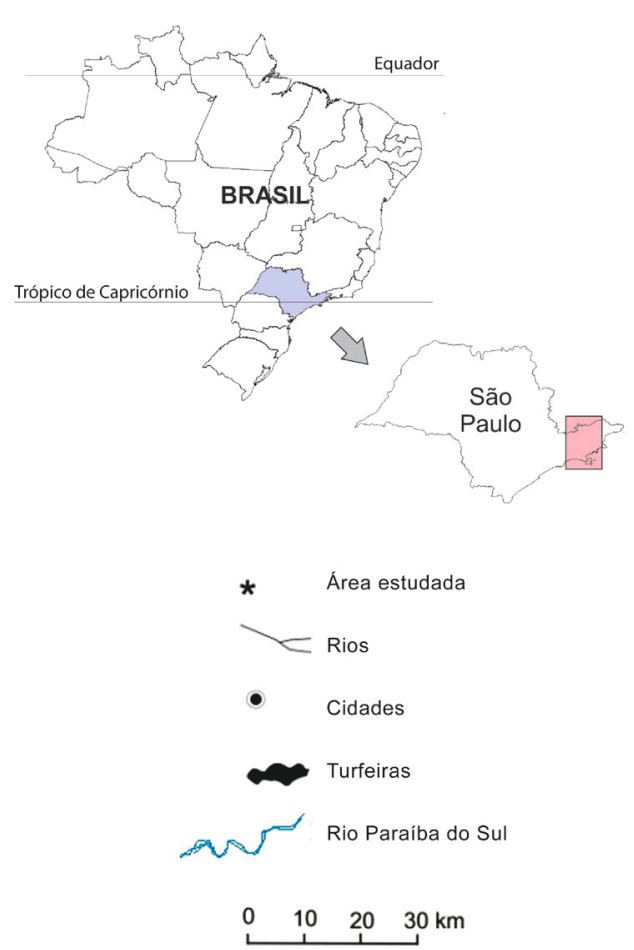

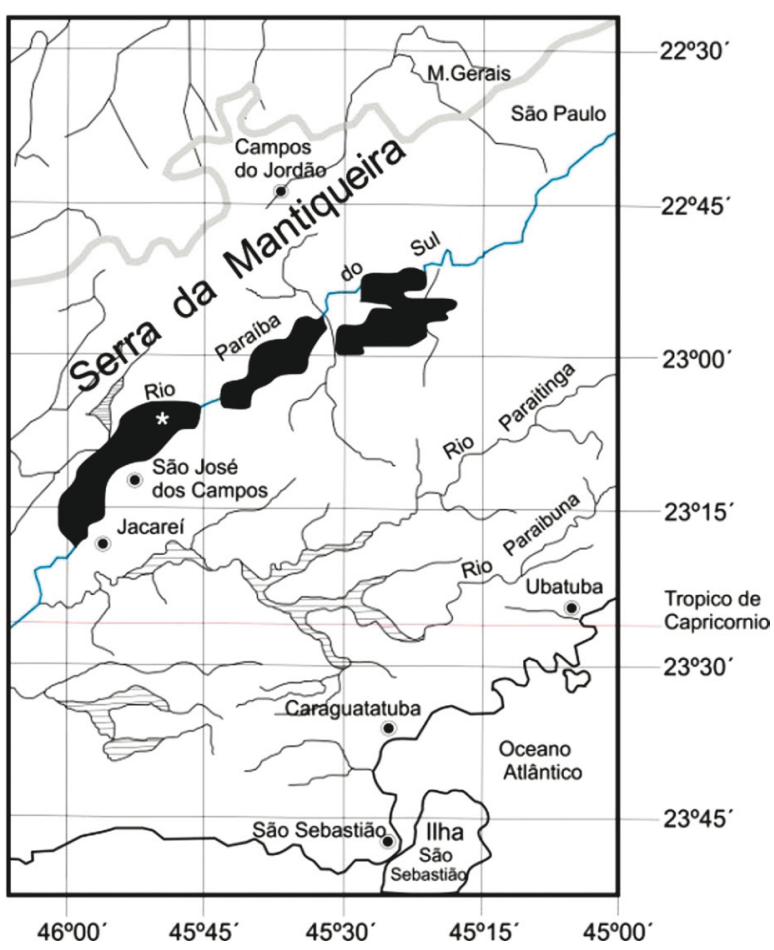

FIGURA 1 - Localização das turfeiras do médio vale do rio Paraíba do Sul, estado de São Paulo (Modificado de GARCIA et al. 2004).

permaneceu estabilizado por muito tempo, caso contrário, a bacia orgânica teria sido em grande parte destruída. Este fato também foi constatado por GARCIA (1994) em testemunhos com cerca de $6 \mathrm{~m}$ de espessura de turfa, com argila plástica na base ou areia conglomerática, que forneceram idades na base de 14.000 a 9.000 anos AP e no topo de 4.000 a $1.500 \mathrm{AP}$. Na mina de exploração de turfa da Eucatex, CASADO (2009) estudou um testemunho com $1,30 \mathrm{~m}$ de areia na base e idade de 22.700 anos AP a +/- 4,30 $\mathrm{m}$ de profundidade. Tais resultados também mostram a estabilidade da bacia orgânica.

Os depósitos arenosos do cinturão meândrico apresentam entre 12 a 14 m e constituem-se de areias grossas a médias, feldspáticas, micáceas, com grânulos e seixos; possuem estratificações cruzadas, acanaladas e planares, com um nível conglomerático na base (MONTANHEIRO 2009).

Segundo a classificação de KÖPPEN (1948), o clima atual dessa região é do tipo Cwa (quente com inverno seco), enquanto nas regiões adjacentes de maiores altitudes, serras do Mar e da Mantiqueira, do tipo $C w b$ (temperado ou quase temperado com inverno seco).

Em relação à vegetação, URURAHY et al. (1983) descrevem que a região do médio vale do rio Paraíba do Sul apresentava originalmente áreas de floresta Ombrófila Mista / floresta de Araucária, floresta Ombrófila Densa / floresta Atlântica Montana, floresta Estacional Semidecidual e Campestre (Cerrado ou Savana), assim como áreas de transição, com formações pioneiras de influência fluvial. Nas últimas décadas, essas áreas foram descaracterizadas e reduzidas a pequenos agrupamentos florestais primários e vegetações campestres, devido às ações antrópicas, como queimadas, instalações urbanas e ocupação com agropecuária (GARCIA et al. 2004).

\section{MATERIAIS E MÉTODOS}

A coluna sedimentar turfosa, de 3,90 m de espessura, foi obtida por SANTOS (2009) com vibro-testemunhador (MARTIN et al. 1995) na margem direita do médio vale do rio Paraíba do 
Sul, a $45^{\circ} 50^{\prime} 3,81^{\prime \prime} \mathrm{W}$ de longitude e $23^{\circ} 07^{\prime} 57$ $36^{\prime} \mathrm{S}$ de latitude. A testemunhagem constou de um tubo de alumínio, com parede de $1,5 \mathrm{~mm}$ de espessura, 2" de diâmetro e $6 \mathrm{~m}$ de comprimento. Esse tubo foi ligado a um mangote por uma braçadeira e esta a um motor de $125 \mathrm{cc}$ para produzir vibração e pressionar a descida do tubo. O tubo de alumínio entrou até o limite de resistência do substrato, sendo então fechado na parte superior, para retenção da coluna turfosa. O tubo foi todo vedado, codificado na base e no topo, e transportado na horizontal até o laboratório.

As amostras para datação radiocarbônica, coletadas nas profundidades de $355,245,205,155$ e $45 \mathrm{~cm}$, foram selecionadas no laboratório de sedimentologia do Instituto de Geociências da Universidade de São Paulo (IGc/USP). As datações foram realizadas no laboratório da Beta Analytic Inc. (EUA) pela técnica da espectrometria de massa acelerada (AMS) e utilizou-se para calibração a curva SHCal13 elaborada para a América do Sul (HOGG et al. 2013).

No laboratório de Geociências da Universidade Guarulhos (UnG) o testemunho foi aberto e as amostras para palinologia coletadas e processadas por SANTOS (2009). Para as análises palinológicas, foram efetuadas coletas de $1 \mathrm{~cm}^{3}$ em intervalos de $5 \mathrm{~cm}$ ao longo do testemunho, totalizando 36 amostras. A extração dos palinomorfos seguiu o protocolo estabelecido por COLINVAUX et al. (1999), assim sumariado:

1) adição, a cada amostra, de uma pastilha com 13.340 esporos exóticos de Lycopodium clavatum. Segundo STOCKMARR (1972), a adição e contagem de Lycopodium possibilita o cálculo das concentrações polínicas por $\mathrm{cm}^{3} \mathrm{de}$ sedimento.

2) tratamento químico com ácidos fluorídrico e clorídrico para dissolver os silicatos e os silicofluoretos, hidróxido de potássio para oxidar e eliminar o excesso da matéria orgânica e solução acetólise para eliminar o provável protoplasma ainda presente. Em todas as etapas, as amostras foram centrifugadas com água destilada por três vezes até a eliminação do reagente. Após a acetólise, as amostras foram centrifugadas com ácido acético glacial, acrescentadas de oito gotas de glicerina e colocadas em estufa a $40{ }^{\circ} \mathrm{C}$ por $8 \mathrm{~h}$.

As lâminas foram montadas em glicerina e as bordas da lamínula vedadas com parafina derre- tida, identificadas sob os códigos: EU 0 a EU 360 e depositadas no laboratório de Micropaleontologia do IGc/USP.

A análise óptica foi realizada com o microscópio Olympus BX40 e/ou BX51, em aumentos de 600x e 1.000x. Os esporos e corpos frutíferos de fungos foram fotomicrografados e identificados. As descrições morfológicas e identificações taxonômicas basearam-se em bibliografias especializadas, tais como VAN GEEL (1978), VAN GEEL et al. (1980), PALS et al. (1980), SILVEIRA (1981), LORSCHEITTER (1984), HERRERA \& ULLOA (1990), GARCIA (1994), CARVALHO (1996), GARCIA (1997), NEVES (1998), KALGUTKAR \& JANSONIUS (2000), GRANDI \& SILVA (2003), MEDEANIC et al. (2004), FERREIRA et al. (2005), LEAL \& LORSCHEITTER (2006), VAN GEEL et al. (2011), GELORINI et al. (2011), FREITAS \& CARVALHO (2011), entre outros.

Em cada amostra foram contados 300 esporos de fungos variados, concomitantemente ao esporo exótico de Lycopodium clavatum, utilizado como marcador. Os resultados obtidos foram apresentados sob a forma de diagramas, construídos a partir dos programas Tilia e Tilia Graph (GRIMM 1987). Para a elaboração dos intervalos palinológicos foram selecionados 40 táxons numericamente abundantes, com significado ecológico potencial para as interpretações paleoambientais. Estes dados foram gerados pelo Programa CONISS, subprograma do Tilia Graph.

As lâminas palinológicas e as datações radiométricas foram estudadas nas dissertações de SANTOS (2009) e SILVA (2015). O primeiro analisou algas, esporos de briófitas e pteridófitas e grãos de pólen de gimnospermas e angiospermas, enquanto o segundo, palinomorfos de fungos. As interpretações paleoambientais de ambos os trabalhos são aqui discutidas.

\section{RESULTADOS}

\subsection{Idades}

As datações ${ }^{14} \mathrm{C}$ das amostras da turfeira de Eugênio de Melo foram calibradas de acordo com o programa estatístico Bacon (BLAAUW \& CHRISTEN 2011), o qual usa a curva SHCal13 elaborada para a América do Sul (HOGG et al. 2013). As idades encontram-se entre 11.240 e 300 cal. anos AP (Tabela 1). 
TABELA 1 - Datações radiocarbônicas AMS dos sedimentos da turfeira de Eugênio de Melo. As idades foram calibradas de acordo com a curva SHCal13 (BLAAUW \& CHRISTEN 2011).

\begin{tabular}{cccc}
\hline$N^{\circ}$ Laboratório & Amostra & $\begin{array}{c}\text { Idade convencional } \\
\text { (anos AP) }\end{array}$ & $\begin{array}{c}\text { Idade calibrada } \\
\text { (anos AP) }\end{array}$ \\
\hline Beta-238531 & EM3/A & $310 \pm 40$ & 300 \\
Beta-247976 & EU-03 & $850 \pm 40$ & 740 \\
Beta-238532 & EM3/B & $7.970 \pm 50$ & 9.210 \\
Beta-238533 & EM3/C & $8.980 \pm 50$ & 9.910 \\
Beta-238534 & EM3/D & $9.890 \pm 50$ & 11.240 \\
\hline
\end{tabular}

\subsection{Análises qualitativa e quantitativa}

A análise quantitativa de palinomorfos fúngicos (Figuras 2 e 3) permitiu a elaboração de palinodiagramas de concentração (Figuras 4,5 e 6), segundo sua ecologia e/ou hábitos alimentares (parasitas de animais, saprófitos, habitantes de solos, parasitas de vegetais, patógenos de vegetais, coprófitos, predadores gerais, diversos e indeterminados). A partir dos diagramas de CONISS, foram estabelecidos três intervalos palinológicos.
No que tange à afinidade e ecologia procurou-se comparar os esporos de fungos quaternários com espécimes atuais, que apresentam características morfológicas similares. No entanto, verificou-se que diferentes esporos podem ser produzidos por diferentes gêneros e espécies atuais. Os indicadores paleoecológicos dos espécimes aqui citados são apresentados na tabela 2. A sistemática ora utilizada é artificial e se relaciona apenas com a morfologia.

TABELA 2 - Ecologia dos morfotipos fósseis, segundo a comparação com gêneros e espécies atuais e respectivos autores.

\begin{tabular}{|c|c|c|}
\hline Morfotipos & Afinidades botânicas & Indicadores paleoecológicos \\
\hline Anatolinites sp.1 & $\begin{array}{l}\text { Pestalotiopsis sp. } \\
\text { STEYAERT (1949) }\end{array}$ & $\begin{array}{l}\text { Espécie patógena responsável por necroses foliares em } \\
\text { bananeiras (FURTADO 2011) }\end{array}$ \\
\hline Anatolinites sp.3 & Cordana crassa THÓT (1975) & Espécie saprófita de galhos mortos (RÉVAY 1985) \\
\hline Anatolinites sp.4 & $\begin{array}{c}\text { Anungitopsis triseptata (MATSUSHIMA) } \\
\text { CASTANEDA \& KENDRICK (1991) }\end{array}$ & $\begin{array}{l}\text { Espécie saprófita de folhas mortas de vegetais } \\
\text { (RAMBELLI 2011) }\end{array}$ \\
\hline $\begin{array}{l}\text { Ascodesmisites } \\
\text { malayensis }\end{array}$ & $\begin{array}{l}\text { Clasterosporium caricinum } \\
\text { SCHWEINITZ (1832) }\end{array}$ & $\begin{array}{l}\text { Espécie saprófita de folhas mortas de Carex sp. (VAN } \\
\text { GEEL \& APTROOT 2006) }\end{array}$ \\
\hline Cercosporites torulosus & $\begin{array}{l}\text { Torula herbarum } \\
\text { (PERS.) LINK ex GRAY (1809) }\end{array}$ & $\begin{array}{l}\text { Espécie saprófita de flores mortas de Pistacia lentiscus } \\
\text { (RAMBELLI 2011) }\end{array}$ \\
\hline $\begin{array}{l}\text { Dicellaesporites } \\
\text { inequalibis }\end{array}$ & $\begin{array}{c}\text { Jahnula bipolares } \\
\text { (K.D. HYDE) K.D. HYDE (1999) }\end{array}$ & $\begin{array}{l}\text { Espécie parasita sobre madeiras parcialmente submersas } \\
\text { em água (RAJA \& SHEARER 2006) }\end{array}$ \\
\hline $\begin{array}{l}\text { Dicellaesporites cf. } D \text {. } \\
\text { rinconii }\end{array}$ & $\begin{array}{c}\text { Gymnosporangium sp. } \\
\text { R. HEDWIG ex De CANDOLLE (1805) }\end{array}$ & $\begin{array}{l}\text { Espécie patógena sobre folhas e frutos especialmente de } \\
\text { Cupressaceae e Rosaceae (SILVEIRA 1981) }\end{array}$ \\
\hline Dicellaesporites sp.13 & $\begin{array}{l}\text { Cylindrocarpon destructans } \\
\text { (ZINSMEISTER) SCHOLTEN (1964) }\end{array}$ & $\begin{array}{l}\text { Espécie patógena de vegetais frutíferos (CEDEÑO et al. } \\
\text { 2004) }\end{array}$ \\
\hline $\begin{array}{l}\text { Diporicellaesporites cf. } \\
\text { D. liaoningensis }\end{array}$ & $\begin{array}{l}\text { Byssothecium sp. } \\
\text { FUCKEL (1861) }\end{array}$ & $\begin{array}{l}\text { Espécie parasita sobre substratos lenhosos (VAN GEEL } \\
\text { \& APTROOT 2006) }\end{array}$ \\
\hline Diporicellaesporites sp.9 & $\begin{array}{l}\text { Byssothecium circinans } \\
\text { FUCKEL (1861) }\end{array}$ & $\begin{array}{l}\text { Espécie parasita sobre substratos lenhosos (VAN GEEL } \\
\text { \& APTROOT 2006) }\end{array}$ \\
\hline $\begin{array}{l}\text { Dyadosporites cf. } \\
\text { scabratus }\end{array}$ & $\begin{array}{c}\text { Savoryella lignicola } \\
\text { JONES \& EATON (1969) }\end{array}$ & $\begin{array}{l}\text { Espécie parasita em ambientes aquáticos (ALIAS \& } \\
\text { JONES 2000) }\end{array}$ \\
\hline Eomycetopsis sp.1 & $\begin{array}{c}\text { Uberispora tropicalis } \\
\text { BHAT \& KENDRICK (1993) }\end{array}$ & $\begin{array}{l}\text { Espécie saprófita de cascas de vegetais em decomposição } \\
\text { (CRUZ \& GUSMÃO 2009) }\end{array}$ \\
\hline Foveodiporites sp.1 & $\begin{array}{l}\text { Phialomyces macrosporus } \\
\text { MISRA \& TALBOT (1964) }\end{array}$ & $\begin{array}{l}\text { Espécie saprófita de folhas mortas em solos de restinga } \\
\text { (BARBOSA et al. 2009) }\end{array}$ \\
\hline Foveoletisporonites sp.1 & $\begin{array}{c}\text { Bactrodesmiella aspidospermatis } \\
\text { (BATISTA) PEREZ \& GARNIER (1962) }\end{array}$ & $\begin{array}{l}\text { Espécie predadora de folhas, especialmente Aspidosperma } \\
\text { macrocarpon (DIANESE \& CÂMARA 1994) }\end{array}$ \\
\hline Frasnacritetrus indicus & $\begin{array}{l}\text { Tetraploa aristata } \\
\text { BERKELEY \& BROOME (1850) }\end{array}$ & $\begin{array}{l}\text { Espécie saprófita de folhas e talos vegetais próximo ao } \\
\text { solo (NEVES \& BAUERMANN 2003) }\end{array}$ \\
\hline
\end{tabular}


Continuação da tabela 2

\begin{tabular}{|c|c|c|}
\hline Morfotipos & Afinidades botânicas & Indicadores paleoecológicos \\
\hline Hypoxylonites africanus & $\begin{array}{l}\text { Arthrinium sp. } \\
\text { KUNZE (1817) }\end{array}$ & $\begin{array}{l}\text { Espécie saprófita de folhas, caules e raízes em diferentes } \\
\text { substratos vegetais (CROUS \& GROENEWALD 2013) }\end{array}$ \\
\hline Hypoxylonites lineatus & $\begin{array}{l}\text { Arthrinium phaeospermum (CORDA) } \\
\text { ELLIS (1965) }\end{array}$ & $\begin{array}{l}\text { Espécie patógena de vegetais que causa deterioração em } \\
\text { Albizia falcataria (ASTITI \& SUPRAPTA 2012) }\end{array}$ \\
\hline Hypoxylonites pirozynskii & $\begin{array}{l}\text { Arthrinium sp. } \\
\text { KUNZE (1817) }\end{array}$ & $\begin{array}{l}\text { Espécie saprófita de folhas, caules e raízes em diferentes } \\
\text { substratos vegetais (CROUS \& GROENEWALD 2013). }\end{array}$ \\
\hline $\begin{array}{l}\text { Hypoxylonites } \\
\text { vickburgensis }\end{array}$ & $\begin{array}{l}\text { Arthrinium phaeospermum (CORDA) } \\
\text { ELLIS (1965) }\end{array}$ & $\begin{array}{l}\text { Espécie patógena de vegetais que causa deterioração em } \\
\text { Albizia falcataria (ASTITI \& SUPRAPTA 2012) }\end{array}$ \\
\hline Hypoxylonites sp.1 & $\begin{array}{c}\text { Arthrinium caricicola } \\
\text { KUNZE \& SCHMIDT (1817) }\end{array}$ & $\begin{array}{l}\text { Espécie saprófita que habita partes mortas e em } \\
\text { decomposição de diferentes vegetais hospedeiros } \\
\text { (HANDE et al. 2014) }\end{array}$ \\
\hline Hypoxylonites sp. 2 & $\begin{array}{c}\text { Arthrinium caricicola } \\
\text { KUNZE \& SCHMIDT (1817) }\end{array}$ & $\begin{array}{l}\text { Espécie saprófita que habita partes mortas e em } \\
\text { decomposição de diferentes vegetais hospedeiros } \\
\text { (HANDE } \text { et al. 2014) }\end{array}$ \\
\hline Inapertisporites globosus & $\begin{array}{l}\text { Botryotrichum piluliferum (SACCARDO) } \\
\text { MARCHAL (1885) }\end{array}$ & $\begin{array}{l}\text { Habitante de solos com alta concentração de matéria } \\
\text { orgânica (ULFIG 1994) }\end{array}$ \\
\hline Inapertisporites $\mathrm{sp} .2$ & $\begin{array}{c}\text { Coniochaeta ligniaria (GREVALLE) } \\
\text { MASSEE (1887) }\end{array}$ & $\begin{array}{l}\text { Espécime de hábitos diversos, bastante comum em } \\
\text { estercos e madeiras, superfície de solos e, com forte } \\
\text { evidência de alta densidade populacional de animais } \\
\text { domesticados (VAN GEEL \& APTROOT 2006) }\end{array}$ \\
\hline Inapertisporites $\mathrm{sp} .3$ & $\begin{array}{l}\text { Humicola fuscoatra } \\
\text { TRAAEN (1914) }\end{array}$ & $\begin{array}{l}\text { Habitante de solos colonizandos por raízes de gramíneas/ } \\
\text { poáceas (GRUYTER et al. 1992) }\end{array}$ \\
\hline $\begin{array}{l}\text { Involutisporonites } \mathrm{cf} . \mathrm{I} \text {. } \\
\text { foraminus }\end{array}$ & $\begin{array}{l}\text { Troposporella monospora } \\
\text { (W.B. KENDRICK) M.B. ELLIS (1976) }\end{array}$ & $\begin{array}{l}\text { Espécie saprófita de folhas mortas de vegetais } \\
\text { (RAMBELLI 2011) }\end{array}$ \\
\hline $\begin{array}{l}\text { Lacrimasporonites } \mathrm{cf} . \mathrm{L} . \\
\text { buerglii }\end{array}$ & $\begin{array}{l}\text { Uromyces sp. } \\
\text { UNGER (1816) }\end{array}$ & $\begin{array}{l}\text { Espécie patógena que causa ferrugem nas folhas dos } \\
\text { vegetais (THAUNG 2009) }\end{array}$ \\
\hline Microthyriaceae & $\begin{array}{l}\text { Desmidiospora myrmecophila } \\
\text { THAXTER (1891) }\end{array}$ & $\begin{array}{l}\text { Espécie parasita que vive em solos, comum em formigas } \\
\text { (BAHRAMI et al. 2002) }\end{array}$ \\
\hline $\begin{array}{l}\text { Monoporisporites } \\
\text { oviformis }\end{array}$ & $\begin{array}{c}\text { Podospora anserina (RABENHORST) } \\
\text { NIESSL (1833) }\end{array}$ & $\begin{array}{l}\text { Espécie coprófita, típica de excrementos de animais } \\
\text { (MUNGAY et al. 2012) }\end{array}$ \\
\hline Monoporisporites sp.1 & Indeterminado & Indeterminado \\
\hline Monoporisporites sp.2 & $\begin{array}{c}\text { Conioscypha minutispora } \\
\text { (HERNREST.) GENÉ \& GUARRO } \\
(2014)\end{array}$ & $\begin{array}{l}\text { Espécie saprófita em madeiras mortas, bambus e folhas } \\
\text { (CROUS et al.2014) }\end{array}$ \\
\hline Monoporisporites sp. 3 & $\begin{array}{l}\text { Chaetomium robustum } \\
\text { AMES (1963) }\end{array}$ & $\begin{array}{l}\text { Espécime de hábitos diversos encontrada em solos, } \\
\text { serapilheiras e estercos (KUBÁTOVÁ 2006) }\end{array}$ \\
\hline Monoporisporites sp.4 & $\begin{array}{l}\text { Nigrospora sphaerica (SACCARDO) } \\
\text { MASON (1927) }\end{array}$ & $\begin{array}{l}\text { Espécie patógena que habita caules e folhas de vegetais } \\
\text { (WEBSTER 1952) }\end{array}$ \\
\hline Monoporisporites sp.5 & Indeterminado & Indeterminado \\
\hline Monoporisporites sp.6 & $\begin{array}{c}\text { Sordaria } \text { sp. } \\
\text { CESATI \& DE NOTARIS (1863) }\end{array}$ & $\begin{array}{l}\text { Espécie coprófita, decompositora de excrementos de } \\
\text { animais herbívoros (VAN GEEL \& APTROOT 2006) }\end{array}$ \\
\hline Multicellites sp.9 & $\begin{array}{l}\text { Phaeosphaeria sp } \\
\text { MIYAKE (1909) }\end{array}$ & $\begin{array}{l}\text { Espécie patógena de cereais gramíneas/poáceas } \\
\text { silvestres, ciperáceas e juncos (GELORINI et al. 2011) }\end{array}$ \\
\hline $\begin{array}{l}\text { Papulosporonites } \\
\text { hammenii }\end{array}$ & $\begin{array}{l}\text { Papulaspora sepedonioides } \\
\text { PREUSS (1851) }\end{array}$ & $\begin{array}{l}\text { Espécie de hábitos diversos que vive em uma ampla } \\
\text { variedade de substratos, incluindo plantas, detritos, } \\
\text { produtos de celulose, madeira, esterco, solo, outros } \\
\text { fungos e tecidos animais (DAVEY et al. 2008) }\end{array}$ \\
\hline Quilonia sp.12 & $\begin{array}{l}\text { Corynespora sp. } \\
\text { GUSSOW (1906) }\end{array}$ & $\begin{array}{l}\text { Espécie saprófita e/ou patógena de vegetais que causam } \\
\text { manchas e infecção foliar (KUMAR et al. 2012) }\end{array}$ \\
\hline $\begin{array}{l}\text { Spirotremesporites cf. } S \text {. } \\
\text { simplex }\end{array}$ & $\begin{array}{c}\text { Rosellinia sp. } \\
\text { DE NOTARIS (1844) }\end{array}$ & $\begin{array}{l}\text { Espécie parasita em substratos de plantas herbáceas ou } \\
\text { em madeiras (VAN GEEL et al. 2011) }\end{array}$ \\
\hline $\begin{array}{l}\text { Striadisporites } \\
\text { californicus }\end{array}$ & $\begin{array}{l}\text { Gelasinospora sp. } \\
\text { DOWDING (1933) }\end{array}$ & $\begin{array}{l}\text { Espécie coprófita, decompositora de excrementos } \\
\text { (ALEXOPOULOS et al. 1996). }\end{array}$ \\
\hline Striadisporites sp. 1 & $\begin{array}{l}\text { Gelasinospora cerealis } \\
\text { DOWDING (1933) }\end{array}$ & $\begin{array}{l}\text { Espécie coprófita, decompositora de excrementos } \\
\text { (ALEXOPOULOS et al. 1996) }\end{array}$ \\
\hline
\end{tabular}




\section{- Intervalo I}

O Intervalo I (base do testemunho), compreendido entre as profundidades 360 e $190 \mathrm{~cm}$ e idades entre 11.240 cal. anos AP e 8.930 anos AP (idade interpolada), é constituído por argila na base, sobreposta por turfa sáprica.

Neste intervalo (Figura 4) estão presentes espécimes saprófitas como Anatolinites sp.3 (Figura 2B), Anatolinites sp.4 (Figura 2C), Ascodesmisites malayenses (Figura 2D), Eomycetopsis sp.1 (Figura 2L), Foveodiporites sp.1 (Figura 2M), Frasnacritetrus indicus (Figura 2O), Hypoxylonites africanus (Figura 2P), Hypoxylonites pirozynskii (Figura 2R), Hypoxylonites sp.2 (Figura 3A), Involutisporonites cf. I. foraminus (Figura 3E) e Monoporisporites sp.2 (Figura 3J), em concentrações que atingem dois apogeus (Figura 6): o primeiro com 218.776 esporos $/ \mathrm{cm}^{3}$ a $270 \mathrm{~cm}$ de profundidade e o segundo com 189.838 esporos $/ \mathrm{cm}^{3}$, a $250 \mathrm{~cm}$ de profundidade, ambos em turfa sáprica.

A concentração de espécimes de parasitas de vegetais (Figura 5), tais como Diporicellaesporites cf.D. liaoningensis(Figura2I), Diporicellaesporites sp.9 (Figura 2J) e Dyadosporites cf. D. scabratus (Figura 2K), é relevante apenas na profundidade de $340 \mathrm{~cm}$, com 124.660 esporos $/ \mathrm{cm}^{3}$.

Fungos habitantes de solos, como Inapertisporites globosus (Figura 3B) e Inapertisporites sp.3 (Figura 3D), entre as profundidades de 190 e $340 \mathrm{~cm}$, possuem concentrações de 3.638 esporos $/ \mathrm{cm}^{3}$.

Espécies decompositoras de excrementos, como Monoporisporites sp.6 (Figura 3N), apresentam concentração de 4.850 esporos $/ \mathrm{cm}^{3}$, com três elevações (340, 270 e $190 \mathrm{~cm}$ de profundidade), sendo mais expressivos a $190 \mathrm{~cm}$ de profundidade.

A presença e diversidade de fungos patógenos de vegetais é pequena ao longo do intervalo; distingue-se Monoporisporites sp.4 (Figura 3L), presente na profundidade de $240 \mathrm{~cm}$, em concentrações de 22.575 esporos $/ \mathrm{cm}^{3}$.

Indivíduos com hábitos de parasitas de animais, como primórdios de Microthyriaceae (Figura $3 \mathrm{G}$ ), são raros nesse intervalo (Figura 4), e espécimes de hábitos predadores, em geral (Figura 5), estão ausentes.

Espécimes com hábitos diversos, como Inapertisporites sp.2 (Figura 3C), Papulosporonites hammenii (Figura 3P), Striadisporites californicus (Figura 3S) e Striadisporites sp.1 (Figura 3T), possuem picos de concentração alternados (Figura 4), com máximo de 73.883 esporos $/ \mathrm{cm}^{3}$ a $250 \mathrm{~cm}$ de profundidade.
Indivíduos com hábitos indeterminados, como Monoporisporites sp.5 (Figura 3M), apresentam concentrações mais elevadas na profundidade de $270 \mathrm{~cm}$ (Figura 5), onde atingem 89.378 esporos $/ \mathrm{cm}^{3}$.

Dentre as principais espécies de cada grupo ecológiconesteintervalo(Figuras 4 e 5), destacam-se em concentração: saprófitas - Ascodesmisites malayensis (Figura 2D) (27.865 esporos/ $\mathrm{cm}^{3}$ ), Eomycetopsis sp.1 (Figura 2L) (106.623 esporos $/ \mathrm{cm}^{3}$ ) Foveodiporites sp.1 (Figura 2M) (146.100 esporos $\left./ \mathrm{cm}^{3}\right)$, Hypoxylonites africanus (Figura 2P) (33.411 esporos $\left./ \mathrm{cm}^{3}\right)$, Hypoxylonites pirozinskii (Figura 2R) (32.656 esporos $\left./ \mathrm{cm}^{3}\right)$, Involutisporonites cf. I. foraminus (Figura 3E) (230.265 esporos/cm3) e Monoporisporites sp.2 (Figura 3J) (297.916 esporos/ $\mathrm{cm}^{3}$ ); hábitos diversos - Inapertisporites sp.2 (Figura 3C) (229.924 esporos $\left./ \mathrm{cm}^{3}\right)$, Striadisporites californicus (Figura 3S) (10.618 esporos $\left./ \mathrm{cm}^{3}\right)$, Striadisporites sp.1 (Figura 3T) (35.279 esporos $\left./ \mathrm{cm}^{3}\right)$; hábitos indeterminados - Monoporisporites sp.5 (Figura 3M) (65.720 esporos $/ \mathrm{cm}^{3}$ ); parasitas de vegetais Diporicellaesporites cf. D. liaoningensis (Figura 2I) (197.557 esporos $\left./ \mathrm{cm}^{3}\right)$, Diporicellaesporites sp.9 (Figura 2J) (63.923 esporos $\left./ \mathrm{cm}^{3}\right)$, Dyadosporites cf. D. scabratus (Figura 2K) (8.224 esporos $/ \mathrm{cm}^{3}$ ); e patógenos de vegetais - Monoporisporites sp.4 (Figura 3L) (34.034 esporos $/ \mathrm{cm}^{3}$ ).

Na profundidade entre 300 e $230 \mathrm{~cm}$ há alta concentração de fungos saprófitos, de hábitos diversos, de hábitos indeterminados e coprófitos (Figura 6).

\section{- Intervalo II}

O Intervalo II está localizado entre as profundidades de 190 e $110 \mathrm{~cm}$ e é balizado pelas idades de 8.930 e 550 anos AP (ambas interpoladas). A base deste intervalo corresponde a um hiato de cerca de 7.000 anos, correspondente a uma camada de areia sem datação, que pode representar um intervalo curto da deposição (meses ou até dias) (Figura 6). A camada de areia é sobreposta por uma de argila com idade de 740 cal. anos AP, uma camada espessa de turfa hêmica com idades entre 550 (idade interpolada) e 300 cal. anos AP e, no topo, argila.

Os fungos saprófitos apresentam concentrações menores em relação ao intervalo anterior: na base, 67.912 esporos $/ \mathrm{cm}^{3}$, e, no topo, 208.309 esporos $/ \mathrm{cm}^{3}$, sendo Eomycetopsis sp.1 (Figura 2L), Hypoxylonites pirozynskii (Figura 2R) e 
Hypoxylonites sp.1 (Figura 2T), os mais importantes (Figura 4). Parasitas de animais (primórdios de Microthiriaceae, Figura 3G) estão concentrados desde a base do intervalo II (2.222 esporos $/ \mathrm{cm}^{3}$ ). Os coprófitos atingem concentrações de 4.851 esporos $/ \mathrm{cm}^{3}$ (Figura 5) próximo da base, a 190 $\mathrm{cm}$ de profundidade, sendo Monoporisporites sp.6 (Figura $3 \mathrm{~N}$ ) o esporo mais importante. Os parasitas de vegetais possuem concentrações baixas na base (Figura 6), cerca de 200 esporos $/ \mathrm{cm}^{3}$, atribuídas a Diporicellaesporites cf. D. liaoningensis (Figura 2I) e, mais elevadas no topo (5.493 esporos $/ \mathrm{cm}^{3}$ ), representadas por Dyadosporites cf. D. scabratus (Figura 2K) e Spirotremesporites cf. S. simplex (Figura 3R).

Entre os predadores gerais (Foveoletisporonites sp.1, Figura $2 \mathrm{~N}$ ), a concentração é de 728 esporos $/ \mathrm{cm}^{3}$ (Figura 6). Os habitantes de solos, Inapertisporites sp.3 (Figura 3D) e Inapertisporites globosus (Figura 3B), encontram-se ao longo de todo o intervalo, com concentrações de 3.638 esporos $/ \mathrm{cm}^{3}$ (base), 9.417 esporos/cm3 (topo) e 22.587 esporos $/ \mathrm{cm}^{3}$ (170 e 120 $\mathrm{cm}$ de profundidade) (Figura 6).

Contudo, os patógenos de vegetais (Figura 5), com exceção do esporo Quilonia sp.12 (Figura $3 \mathrm{Q})$, marcam presença neste intervalo, e atingem dois grandes ápices em concentração (14.553 na base e 45.513 esporos $/ \mathrm{cm}^{3}$ topo), com destaque para Anatolinites sp.1 (Figura 2A) com 178.111 esporos $/ \mathrm{cm}^{3}$.

\section{- Intervalo III}

O Intervalo III (Figura 6) localiza-se entre as profundidades de 110 e $0 \mathrm{~cm}$, (idades entre 550 anos AP (interpolada) e atual) e é constituída por turfa hêmica e argila.

Verifica-se que os saprófitos Anatolinites sp.3 (Figura 2B), Anatolinites sp.4 (Figura 2C), Ascodesmisites malayensis (Figura 2D), Eomycetopsis sp.1 (Figura 2L), Foveodiporites sp.1 (Figura 2M), Frasnacritetrus indicus (Figura 2O), Hypoxylonites africanus (Figura 2P), Hypoxylonites pirozynskii (Figura 2R), Hypoxylonites sp.1 (Figura 2T), Hypoxylonites sp.2 (Figura 3A), Involutisporonites cf. I. foraminus (Figura 3E) e Monoporisporites sp.2 (Figura 3J) alternam-se em concentrações ao longo do intervalo e atingem 303.435 esporos $/ \mathrm{cm}^{3}$ na sua totalidade (Figura 6), sendo mais expressivos que os outros grupos. Eomycetopsis sp.1 (Figura 2L),
Hypoxylonites sp.1 (Figura 2T) e Monoporisporites sp.2 (Figura 3J) destacam-se por estarem presentes ao longo de todo o intervalo, em concentrações variáveis (Figura 4).

Os patógenos de vegetais também estão bem representados neste intervalo, com concentrações de 75.000 esporos $/ \mathrm{cm}^{3}$ (Figura 6), com destaque para Dicellaesporites inaequabilis (Figura 2F), Spirotremesporites cf. S. simplex (Figura 3R), Diporicellaesporites sp.9 (Figura 2J) e Dyadosporites cf. D. scabratus (Figura 2K), este último com maior presença (Figura 5).

Os fungos de hábitos diversos possuem concentrações de 25.140 esporos $/ \mathrm{cm}^{3}$, com destaque para Monoporisporites sp.3 (Figura 3K) e Papulosporonites hammenii (Figuras 3P e 4).

Os habitantes de solos têm concentrações de 15.000 esporos $/ \mathrm{cm}^{3}$ (Figura 6); Inapertisporites globosus (Figura 3B) e Inapertisporites sp.3 (Figura 3D) alternam-se como os esporos mais presentes ao longo do intervalo (Figura 5).

Os parasitas de vegetais contabilizam a maior parcela da concentração total de 12.828 esporos $/ \mathrm{cm}^{3}$ (Figura 6) e incluem Dicellaesporites inequabilis (Figura 2F), Diporicellaesporites sp.9 (Figura 2J), Dyadosporites cf. D. scabratus (Figura 2K) e Spirotremesporites cf. S. simplex (Figura 3R), com destaque para os dois últimos (Figura 5). Os predadores contabilizam concentração de 5.000 esporos $/ \mathrm{cm}^{3}$ (Figura 6), sendo Foveoletisporonites sp.1 (Figura $2 \mathrm{~N}$ ) o principal esporo, relacionado às condições ambientais atuais (Figura 5).

Os coprófitos atingem concentrações de 3.800 esporos $/ \mathrm{cm}^{3}$ (Figura 6), representado por duas espécies: Monoporisporites oviformis (Figura $3 \mathrm{H}$ ) e Monoporisporites sp.6 (Figura 3N), a segunda em maior concentração (Figura 5).

Os parasitas de animais estão representados apenas por primórdios de Microthyriaceae (Figura 3G) nesse intervalo (Figura 4). As concentrações são muito baixas, com três ápices nas seguintes profundidades: 667 esporos $/ \mathrm{cm}^{3}$ a $90 \mathrm{~cm}, 620$ esporos $/ \mathrm{cm}^{3}$ a $30 \mathrm{~cm}$ e 635 esporos $/ \mathrm{cm}^{3}$ a $10 \mathrm{~cm}$ (Figura 6).

Osesporosindeterminados, Monoporisporites sp.1 (Figura 3I), presentes próximo ao topo, e Monoporisporites sp.5 (Figura 3M), desde a base $(100 \mathrm{~cm})$ até aproximadamente $40 \mathrm{~cm}$ de profundidade, somam concentrações de 58.363 esporos $/ \mathrm{cm}^{3}$ (Figura 5). 


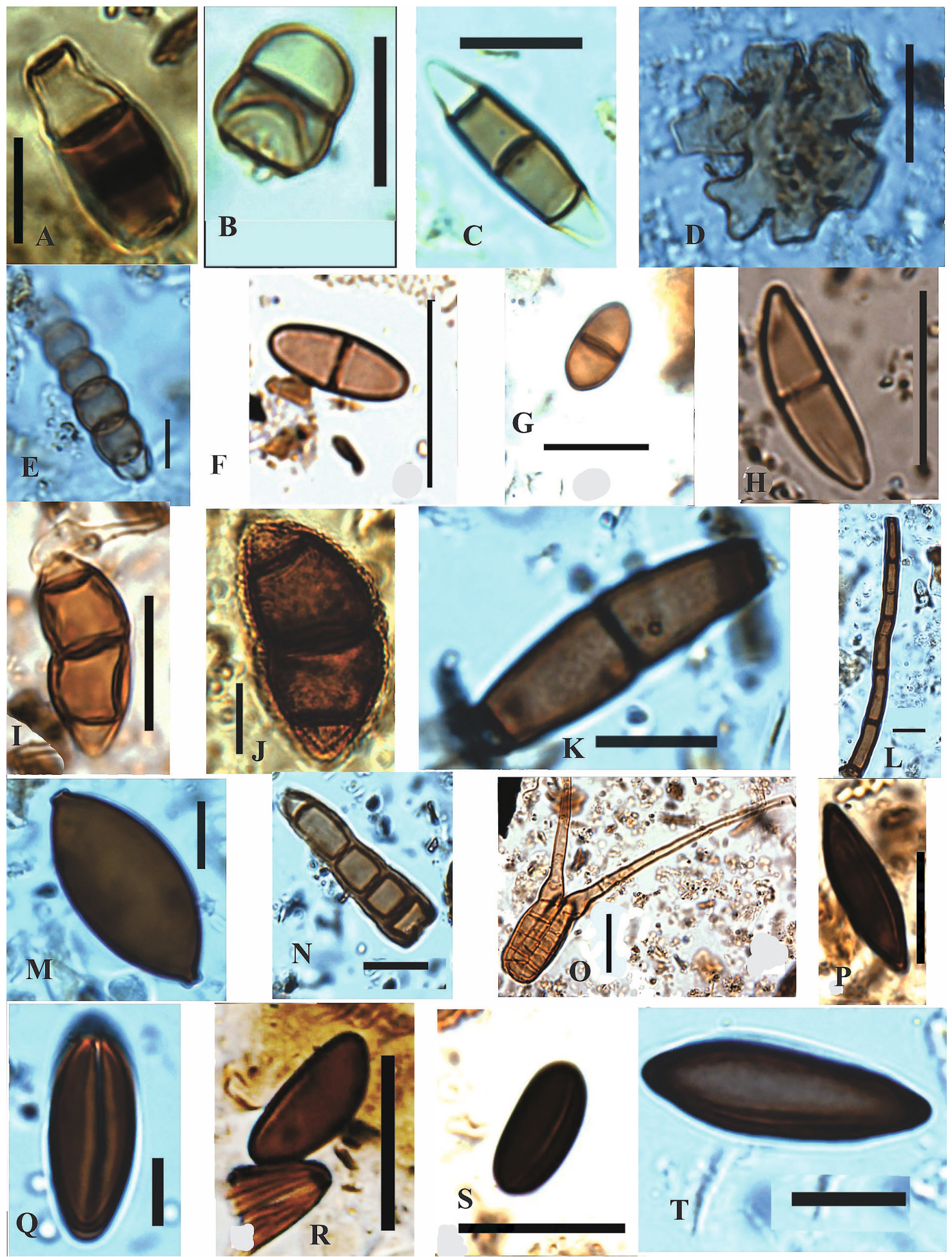

FIGURA 2 - Palinomorfos de fungos: A) Anatolinites sp.1; B) Anatolinites sp.3; C) Anatolinites sp.4; D) Ascodesmisites malayensis; E) Cercosporites torulosus; F) Dicellaesporites inaequalibis; G) Dicellaesporites cf. D. rinconii; H) Dicellaesporites sp.13; I) Diporicellaesporites $\mathrm{cf}$. D. liaoningensis; J) Diporicellaesporites sp.9; K) Dyadosporites cf. D. scabratus; L) Eomycetopsis sp.1; M) Foveodiporites sp.1; N) Foveoletisporonites sp.1; O) Frasnacritetrus indicus; P) Hypoxylonites africanus; Q) Hypoxylonites lineatus; R) Hypoxylonites pirozynkii; S) Hypoxylonites vickburgensis; T) Hypoxylonites sp.1 (Escala gráfica $=10 \mu \mathrm{m}$ ). 

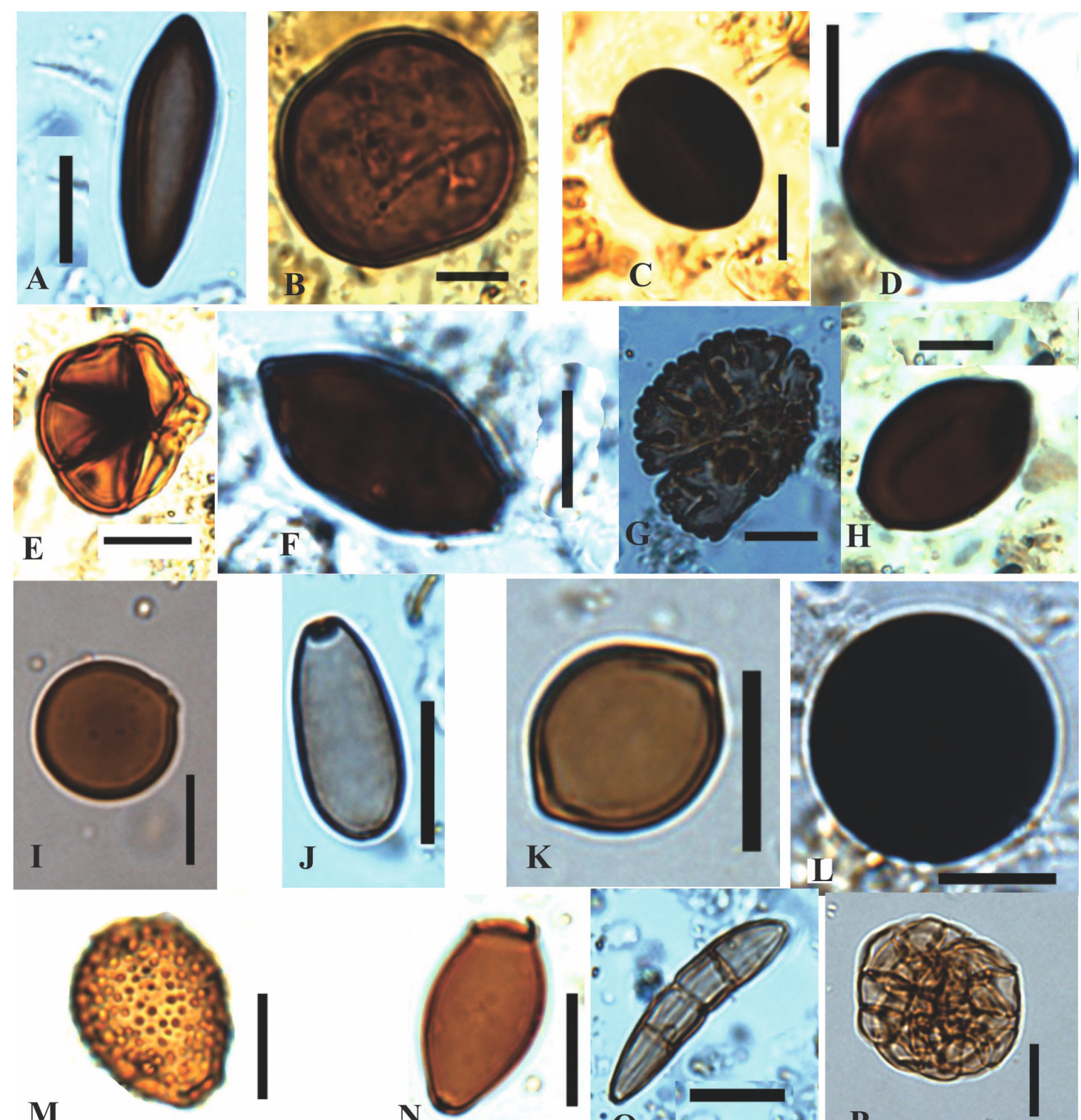

\section{M}
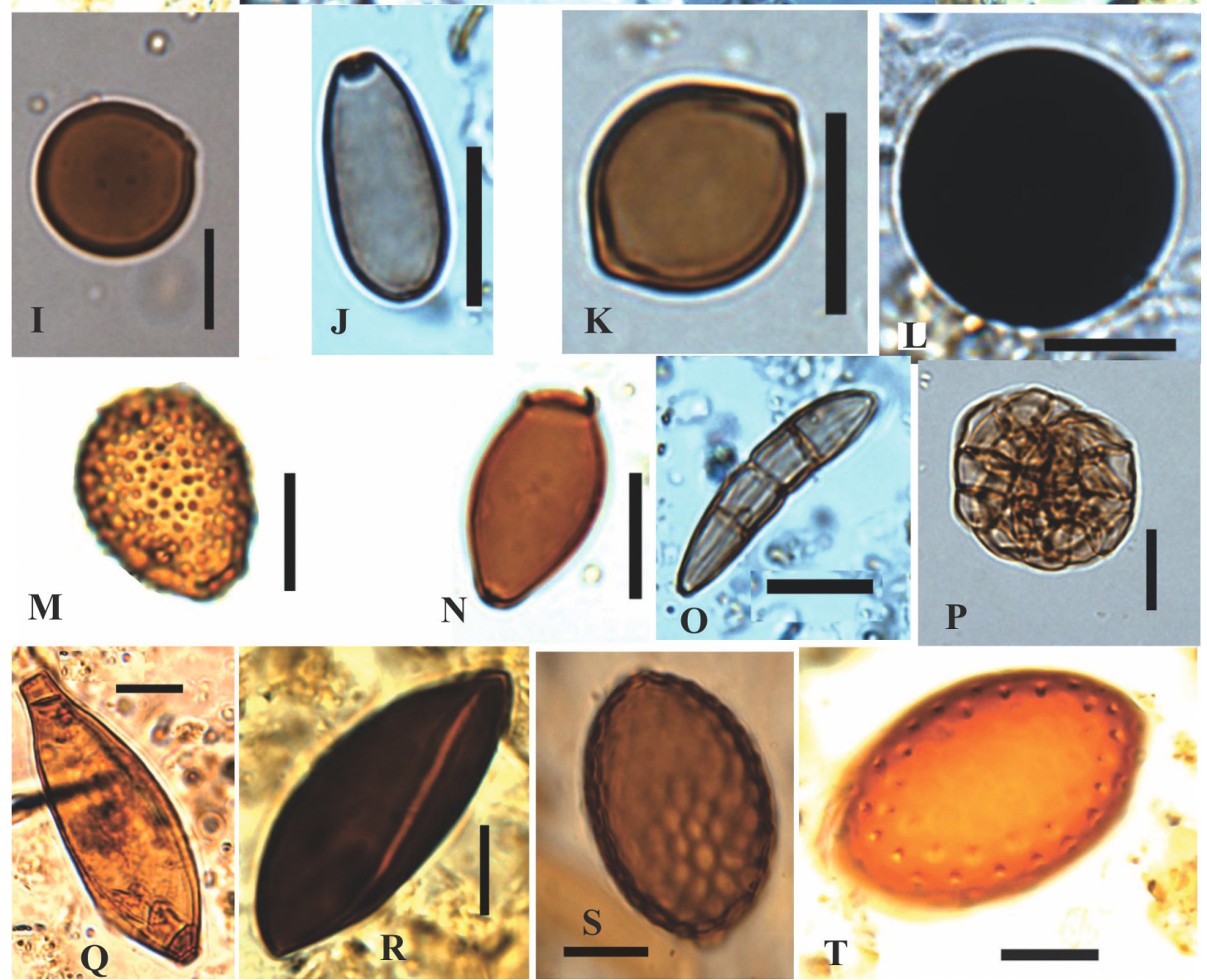

FIGURA 3 - Palinomorfos de fungos: A) Hypoxylonites sp.2; B) Inapertisporites globosus; C) Inapertisporites sp.2; D) Inapertisporites sp.3; E) Involutisporonites cf. I. foraminus; F) Lacrimasporonites cf. L. buerglii; G) Microthyriaceae; H) Monoporisporites oviformis; I) Monoporisporites sp.1; J) Monoporisporites sp.2; K) Monoporisporites sp.3; L) Monoporisporites sp.4; M) Monoporisporites sp.5; N) Monoporisporites sp.6; O) Multicellites sp.9; P) Papulosporonites hammenii; Q) Quilonia sp.12; R) Spirotremesporites cf. S. simplex; S) Striadisporites californicus; T) Striadisporites sp.1 (Escala gráfica $=10 \mu \mathrm{m}$ ). 


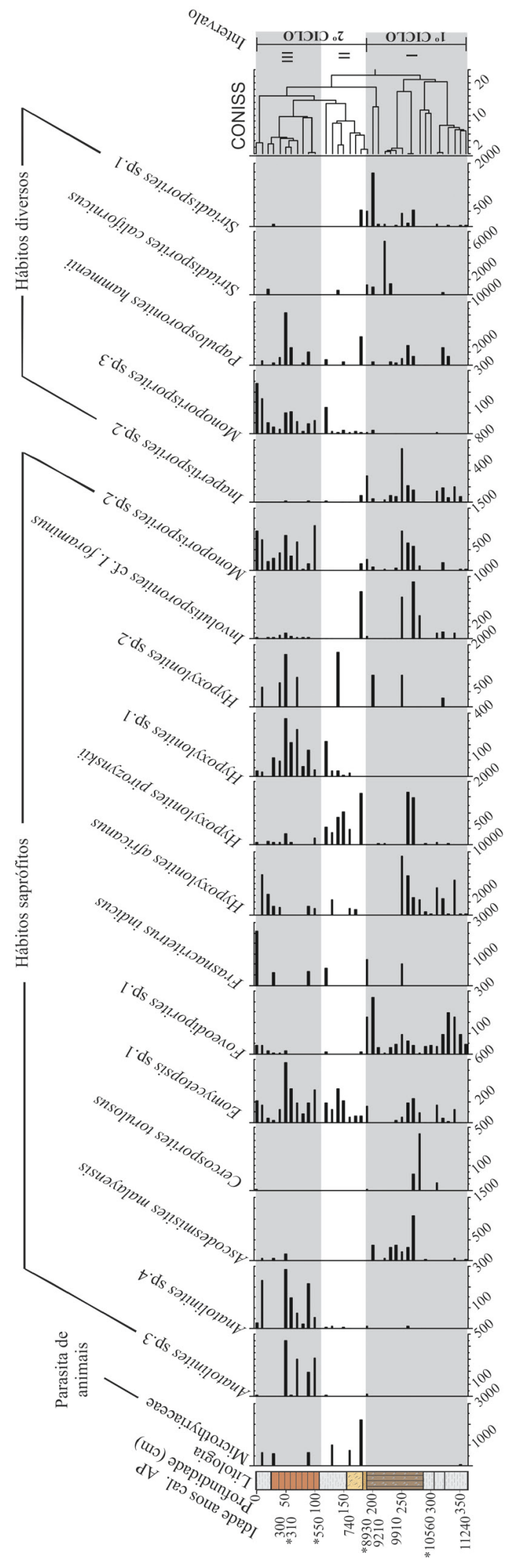

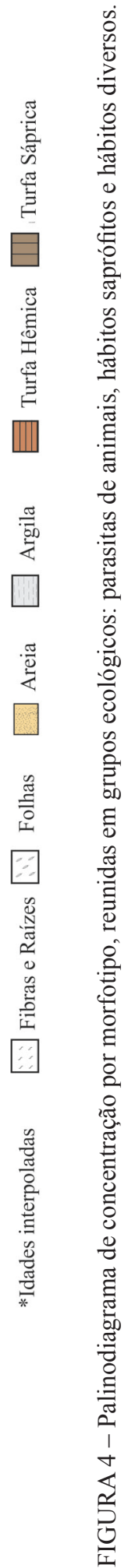




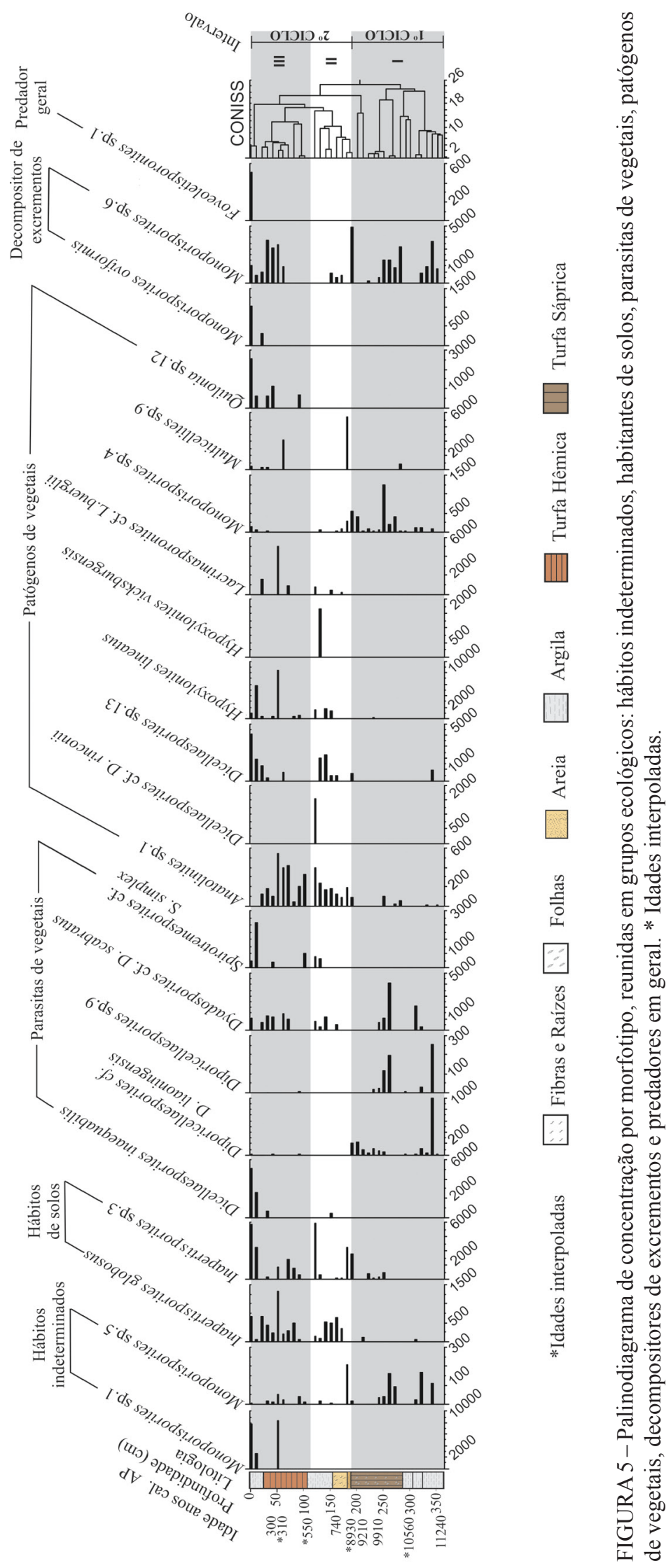




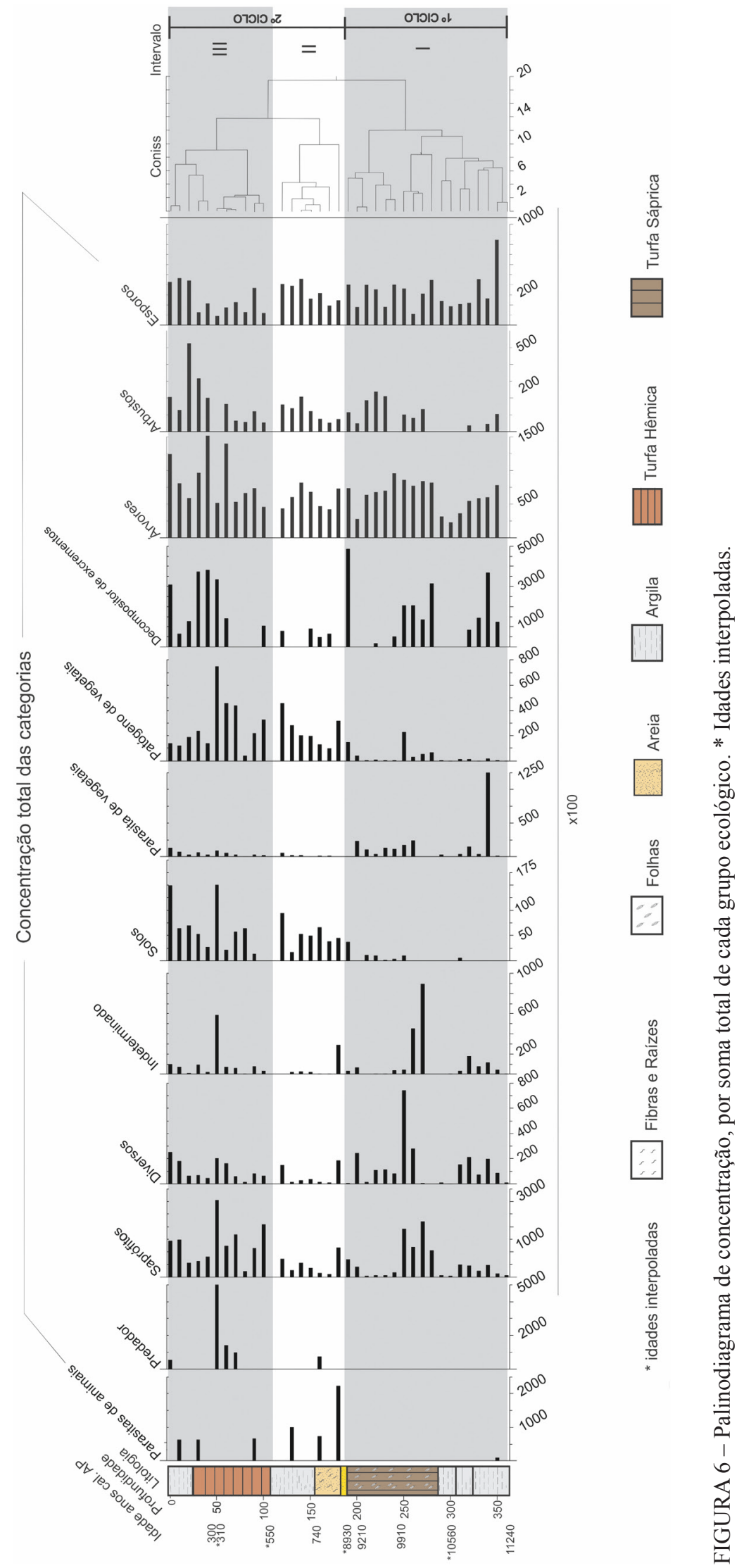




\subsection{O ambiente de deposição}

O testemunho analisado (Figura 6) mostrou a presença de dois ciclos de deposição (ciclo $1=$ Intervalo I; ciclo II = Intervalos $I I$ e $I I I)$. O primeiro ocorreu no intervalo de 11.240 cal. anos AP até cerca de 8.930 anos AP (idade interpolada), entre as profundidades de 360 e $190 \mathrm{~cm}$. A areia presente na base da coluna sedimentar, entre as profundidades 390 e $370 \mathrm{~cm}$, é aqui atribuída a depósitos de canal fluvial. O abandono do canal, ou a sua migração para além do ponto de amostragem, permitiu a formação de um lago, ou de uma sedimentação em planície de inundação com a consequente deposição de sedimento mais fino (argila). Posteriormente, a instalação de vegetação, avançando progressivamente na planície de inundação, propiciou a formação da turfa sáprica. É provável que uma vegetação de maior porte tenha colonizado a área num segundo momento, contribuindo para o assoreamento. $\mathrm{O}$ topo da turfa sáprica, datada de 8.930 anos AP (idade interpolada), é o limite superior do primeiro ciclo.

O segundo ciclo corresponde ao intervalo entre a profundidade de $190 \mathrm{~cm}$ e o topo, com deposição inicial de sedimentos arenosos há 740 cal. anos $\mathrm{AP}$, provavelmente rápida e com fragmentos vegetais subfossilizados (entre 190 e 150 $\mathrm{cm})$. Esses sedimentos permitem interpretar a migração e o reposicionamento do canal, evidenciado pelo aumento da energia deposicional; logo após, o canal novamente abandona ou afasta-se da planície de inundação e as condições de sedimentação calmas se reestabelecem no local. Segue-se a sedimentação de argila (entre 145 e $110 \mathrm{~cm}$ ) com idades entre 700 cal. anos AP e 550 cal. anos AP. Instala-se a vegetação que formou a turfa hêmica (entre 110 e $30 \mathrm{~cm}$ ), com idades entre $105 \mathrm{cal}$. anos AP e 300 cal. anos AP, próximo ao topo, e posteriormente nova camada de argila, sem datação.

Os dois ciclos de sedimentação são separados por um hiato de cerca de 7.000 anos, visto que, encerra-se o primeiro ciclo a 8.930 anos AP e, a partir deste, inicia-se, o segundo.

Como se pode verificar, a formação da turfa ocorreu nos dois ciclos deposicionais, a primeira por volta de 10.440 anos AP (idade interpolada) até 8.930 anos AP (idade interpolada) e a segunda, entre 550 anos AP (idade interpolada) e ultrapassa 300 cal. anos AP.

Assim pode-se verificar que o ambiente de deposição se trata de uma planície de inundação brejosa, com sistema fluvial meandrante, sujeito a migração e reposicionamento do canal.

\section{DISCUSSÃO E CONSIDERAÇÕES PALEOECOLÓGICAS}

O reconhecimento da paleomicobiota e seus possíveis atributos ecológicos fornecem dados relevantes para a reconstrução paleoambiental e paleoclimática.

A turfa, em geral, desenvolve-se pela deposição de vegetais em bacias orgânicas redutoras, cujas condições euxínicas propiciam o desenvolvimento de grande diversidade de fungos, especialmente os saprófitos, sobre a matéria vegetal em decomposição. Dentre os palinomorfos anamórficos encontrados, a maioria é da classe dos Hyphomycetes, que também é a mais numerosa. Tem como características a produção de conídios por reprodução assexuada, além da presença de uma grande diversidade de formas e adaptações ao meio ambiente, como verificado nas serrapilheiras que cobrem o solo das florestas tropicais.

No Intervalo I, como visto anteriormente, a comunidade de fungos saprófitos apresenta-se em altas concentrações com dois picos: 218.776 espo$\mathrm{ros} / \mathrm{cm}^{3}$ a $270 \mathrm{~cm}$ e 189.838 esporos $/ \mathrm{cm}^{3}$ a $250 \mathrm{~cm}$ de profundidade (Figura 6).

Segundo KUTORGA et al. (2003) a diversidade e a quantidade de fungos saprófitos relacionam-se à abundância de plantas herbáceas, arbustos e madeiras mortas, sob condições climáticas quentes e úmidas. Essa interpretação pode ser corroborada pelos dados de SANTOS (2009), que constatou a ocorrência de palinomorfos de ervas, arbustos e árvores no primeiro ciclo da coluna sedimentar. A espécie Ascodesmisites malayensis (Figura 2D) é um saprófito de folhas mortas de certas espécies de Cyperaceae (VAN GEEL \& APTROOT 2006) e sua ocorrência com concentração de 27.865 espo$\mathrm{ros} / \mathrm{cm}^{3}$ (Figura 4) sugere também a presença de água, como em charcos ou lagos. SANTOS (2009) encontrou no mesmo horizonte estratigráfico grãos de pólen de Cyperaceae associados a outros palinomorfos, que evidenciam existência de corpos de água com pelo menos $1 \mathrm{~m}$ de profundidade.

Os fungos decompositores de vegetais, Cercosporites torulosus (Figura 2E), Eomycetopsis sp.1 (Figura 2L), Foveodiporites sp.1 (Figura 2M), Frasnacritetrus indicus (Figura2O), Hypoxylonites africanus (Figura 2P), Hypoxylonites pirozynski (Figura 2R), Hypoxylonites sp.2 (Figura 3A), Involutisporonites cf. I. foraminus (Figura 3E) e Monoporisporites sp.2 (Figura 3J) são os saprófitos mais representativos do intervalo I (Figura 4), entre as idades de 11.240 cal. anos AP e 8.930 anos AP. (interpolada). Desenvolvem-se sobre flores, caules, 
troncos e ramos mortos, cascas em decomposição, folhas mortas, raízes de uma série de diferentes substratos vegetais, frutos e bambu (NEVES \& BAUERMANN 2003, BARBOSA et al. 2009, CRUZ \& GUSMÃO 2009, RAMBELLI 2011, CROUS \& GROENEWALD 2013, HANDE et al. 2014, CROUS et al. 2014).

Outra categoria bem representada no intervalo I (Figura 6) é a dos fungos de hábitos diversos, com destaque para Inapertisporites sp.2 (Figura 3C), que ocorre em grandes concentrações (cerca de 229.924 esporos $/ \mathrm{cm}^{3}$ ) (Figura 4) e apresenta hábitos comuns sobre esterco, madeiras e superfície de solo (VAN GEEL \& APTROOT 2006). Estão também associados com esses hábitos, os espécimes Striadisporites sp.1 (Figura 3T) (35.279 esporos $/ \mathrm{cm}^{3}$ ) e Striadisporites californicus (Figura 3S) (10.618 esporos $/ \mathrm{cm}^{3}$ ), que se tornam mais abundantes do meio ao topo do intervalo e são comuns em solos, raízes, restos vegetais e, especialmente coprófitos (Figura 4). Esta associação é sugestiva de presença de animais, principalmente aves (ALEXOPOULOS et al. 1996).

Representantes de fungos parasitas de vegetais como Diporicellaesporites $\mathrm{cf}$. D. liaoningensis (Figura 2I) habitam substratos lenhosos viventes (VAN GEEL \& APTROOT 2006). A presença deste esporo de fungo (197.557 esporos $/ \mathrm{cm}^{3}$ ) no intervalo III (Figura 5) sugere a existência de vegetação de maior porte, relacionadas a plantas do ciclo C3. Estas interpretações estão de acordo com os grãos de pólen de árvores (Alchornea, Anacardiaceae, Hedyosmum, Ilex e outros) identificados por SANTOS (2009). É importante ressaltar que a presença desta espécie é rara do início do intervalo II até próximo ao final do intervalo III.

Outra espécie parasita presente em concentrações relevantes $\left(63.923\right.$ esporos $\left./ \mathrm{cm}^{3}\right)$, Diporicellaesporites sp.9 (Figura 2J), também habita substratos lenhosos (VAN GEEL \& APTROOT 2006), o que lhe confere similaridade, em termos ecológicos, com a espécie anterior (Figura 5).

O Intervalo II (Figura 6) tem início após o hiato (7.000 anos) e antes de +/- 840 anos AP (idade interpolada), relacionado a não deposição de sedimentos, ou, em função de sua erosão.

A comunidade de fungos saprófitos do intervalo II é menor em relação ao anterior, cerca de 67.912 esporos $/ \mathrm{cm}^{3}$ na base e 208.309 esporos/ $\mathrm{cm}^{3}$ no topo, porém ainda permanece como principal responsável pela paleomicobiota (Figura 6). Paralelamente, encontram-se fungos patógenos de vegetais, dos quais Anatolinites sp.1 (Figura 2A), patógeno foliar, apresenta a maior concentração
(178.111 esporos $/ \mathrm{cm}^{3}$ ) (Figura 5). Isto demonstra a abundância de vegetação arbórea. Sua ocorrência em sedimentos arenosos, em geral pobres em matéria orgânica, indica que se trata de material transportado.

A categoria dos fungos de solos (Figura 6) apresenta, além dos decompositores, aqueles associados às raízes das gramíneas (GRUYTER et al. 1992), como por exemplo os micorrízicos (Inapertisporites sp.3, Figura 3D), presentes no início (3.638 esporos $/ \mathrm{cm}^{3}$ ) e no final (9.417 espo$\mathrm{ros} / \mathrm{cm}^{3}$ ) deste intervalo, nas profundidades $190 \mathrm{~cm}$ e $110 \mathrm{~cm}$, respectivamente (Figura 5). Sua ocorrência sugere também indícios de vegetação rasteira e matas próximas às turfeiras, devido às atividades micorrízicas entre as raízes dos vegetais vivos.

Fungos coprófitos como Monoporisporites sp.6, ocorrem em concentrações relativamente baixas (4.851 esporos $\left./ \mathrm{cm}^{3}\right)$, na base deste intervalo $(190 \mathrm{~cm})$, enquanto aqueles de hábitos diversos, Striadisporites californicus (Figura 3S) e Striadisporites sp.1 (Figura 3T) possuem quantidades constantes ao longo do intervalo. Os dois grupos apontam para a presença de animais (Figuras 4 e 5).

No Intervalo III (Figura 6), a partir de 550 anos AP (idade interpolada), torna-se alta a concentração de fungos saprófitos (303.435 esporos/ $\mathrm{cm}^{3}$ ); dentre os de maior incidência, destacam-se: Monoporisporites sp.2 (Figura 3J), cuja associação característica é com madeiras mortas, bambu e folhas (CROUS et al. 2014), Hypoxilonites sp.1 (Figura 3T), associado a partes mortas e em decomposição de diferentes vegetais hospedeiros (HANDE et al. 2014), Eomycetopsis sp.1 (Figura $2 \mathrm{~L}$ ), que costuma se desenvolver sobre cascas em decomposição (CRUZ \& GUSMÃO 2009) e Anatolinites sp.3 (Figura 2B) e A. sp.4 (Figura 2C), encontrados em galhos e folhas mortos próximo de córregos (RÉVAY 1985, RAMBELLI 2011), (Figura 4). Essa matéria orgânica favoreceu a formação da turfa hêmica.

Grande parte dos saprófitos aqui citados são Hyphomycetes e seus registros mostram que muitos são encontrados associados à água doce estagnada (KAR et al. 2010). Tais observações corroboram a identificação na ecozona IV de SANTOS (2009) de palinomorfos relacionados à vegetação aquática (Lentibulariaceae, Polygonaceae e Cyperaceae) e algas (Zygnema, Debarya e Botryococcus).

Um número expressivo de fungos patógenos de vegetais (Tabela 2), especialmente Anatolinites sp.1 (Figura 2A), espécie responsável por necroses foliares (FURTADO 2011), possui grande concentração, com um máximo de 55.027 esporos $/ \mathrm{cm}^{3}$ 
na turfa hêmica (Figura 5). Já próximo ao topo do intervalo III, ocorrem outras espécies patógenas, tais como: Hypoxylonites lineatus (Figura 2Q, 7.060 esporos $\left./ \mathrm{cm}^{3}\right)$, que provoca deterioração em espécies da família Fabaceae (ASTITI \& SUPRAPTA 2012), Dicellaesporites sp.13 (Figura 2H) $\left(7.280\right.$ esporos $\left./ \mathrm{cm}^{3}\right)$, que ataca os vegetais frutíferos e induzem apodrecimento (CEDEÑO et al. 2004), e Lacrimasporonites cf. L. Buerglii (Figura 3F) (1.588 esporos $\left./ \mathrm{cm}^{3}\right)$, que produz ferrugem nas folhas dos vegetais (THAUNG 2009). Essas consequências patogênicas estão associadas à presença de água na superfície das folhas, fator essencial para o início de infecção pelo fungo. Este "molhamento foliar" pode ser ocasionado tanto pelo orvalho como pelas chuvas, favorecendo o processo de infecção. O desencadeamento dos processos patogênicos varia de acordo com as exigências de cada patógeno, que está relacionado com o período de duração do molhamento foliar (DPMF), já que certos fungos necessitam de longos e contínuos períodos de água livre, enquanto outros curtos ou toleram intervalos de seca (VALE et al. 2004).

Portanto, sugere-se que a atividade micobiota patogênica ocorra por influência de temperaturas mais frias, em locais ocupados por matas, fato que corrobora a interpretação feita por SANTOS (2009), pela presença de mata-galeria aberta nesse intervalo, com vegetação constituída por elementos arbóreo-arbustivos.

Os fungos coprófitos não são um grupo tão numeroso, mas uma espécie em particular, Monoporisporites sp.6 (Figura 3N), possui hábitos alimentares em excrementos de animais herbívoros (VAN GEEL \& APTROOT 2006). Mais de 30\% do seu total (concentração de 3.812 esporos $/ \mathrm{cm}^{3}$ ) encontram-se próximos ao topo deste intervalo (Figura 6), entre as idades de 320 e 310 anos AP, possivelmente associados à atividade antrópica, que se instalou nessa época no médio vale do rio Paraíba do Sul. Fungos parasitas (primórdios de Microthyriaceae) e predadores de animais (Foveoletisporonites sp.1, Figura 2N), embora em pequenas quantidades nesse intervalo, também podem estar associados a atividades antrópicas (Figuras 4 e 5).

Outro aspecto importante no intervalo III é a presença de fungos com hábitos diversos, cuja espécie com registro de maior relevância é Monoporisporites sp.3 (Figura 3K) (89.704 espo$\operatorname{ros} / \mathrm{cm}^{3}$ ), que vive em solos, serrapilheiras e é também encontrado em estercos (KUBÁTOVÁ 2006). Observa-se no diagrama da figura 4 aumento desta espécie no topo do intervalo, o que pode estar asso- ciado ao acúmulo de matéria orgânica morta em diferentes estágios de decomposição, assim como à atividade antrópica (pecuária). SANTOS (2009) mostrou que nesse mesmo intervalo os elementos arbóreos praticamente desaparecem e são substituídos por vegetação rasteira.

A interpretação de SANTOS (2009) para o intervalo entre 11.240 cal. anos AP e 8.930 anos AP. (interpolada) é de condições climáticas quentes e úmidas, com matéria orgânica resultante da mistura de plantas dos ciclos $\mathrm{C} 3 \mathrm{e} \mathrm{C} 4$ e fitoplâncton, ideia reforçada aqui pela concentração de fungos saprófitos, como Foveodiporites sp.1 (Figura 2M) e Monoporisporites sp.2 (Figura 3J) e suas respetivas atividades ecológicas de decomposição (Figura 4).

Momentos de condições climáticas mais quentes e úmidas ou de mais frio, interpretados por SANTOS (2009), foram aqui confrontados com a paleomicobiota. Alguns esporos fúngicos podem colaborar com as interpretações sobre as variações climáticas e ambientais, uma vez que a atividade fúngica dos decompositores de matéria orgânica morta está relacionada a condições climáticas quentes e úmidas.

É observado que entre 9.110 cal. anos AP e 9.020 anos AP (idade interpolada) os saprófitos aumentam, assim como aqueles de hábitos diversos, como Inapertisporites sp.2 (Figura 3C), muito comum em estercos, madeiras e superfície de solos (Figuras 4 e 6).

SANTOS (2009) propôs que por volta de 9.810 cal. anos AP ocorreu redução no nível de água e que a vegetação de maior porte instalou-se sobre a turfeira. A presença dominante de fungos parasitas de vegetais (Figura 5), como Diporicellaesporites sp.9 (Figura 2J), reforça esta hipótese, devido às atividades de parasitismo em substratos lenhosos. A redução na quantidade dos fungos saprófitos também é sugestiva da falta de água ou umidade, portanto as condições climáticas teriam sido menos úmidas.

Entre 9.110 cal. anos AP e 9.020 anos AP (interpolada), Diporicellaesporites cf. D. liaoningensis (parasita de vegetais, Figura 2I) e Inapertisporites sp.2 (hábitos diversos, Figura 3C), são os mais comuns em atividades de parasitismo e decomposição de excrementos, respectivamente (Figuras 4 e 5). Neste período, o clima teria sido quente com oscilações de umidade, favorecendo o aumento circunstancial destes indivíduos.

No intervalo II, entre 720 cal. anos AP e 560 anos AP. (idade interpolada), ocorreram condições climáticas frias e úmidas. Observa-se elevação na 
quantidade dos espécimes patógenos de vegetais, que, em média, é baixa ao longo de todo o intervalo I, desde o primeiro ciclo deposicional, em 11.240 anos cal. AP. O aumento na concentração destes patógenos (Figura 5), é atribuído à presença de Anatolinites sp.1 (Figura 2A), Dicellaesporites cf. D. rinconii (Figura 2G). Dicellaesporites sp.13 (Figura 2H), Hypoxylonites vicksburgensis (Figura 2S), Hypoxylonites lineatus (Figura 2Q) e Lacrimasporonites cf. L. buerglii (Figura 3F).

A redução da concentração de saprófitos neste mesmo intervalo (Figura 6), de 116.354 para 9.740 esporos $/ \mathrm{cm}^{3}$, permite interpretar que estes dois grupos (patógenos e saprófitos) estão associados a climas inversos em termos de atividades ecológicas. O primeiro a climas mais frios e o segundo a climas mais quentes.

Noperíodo aproximado de 342,8 anosAP(idade interpolada), a micobiota na turfa hêmica (Figuras 4 e 5) é constituída por saprófitos (Anatolinites sp.1, Anatolinites sp.4, Eomycetopsis sp.1, Hypoxylonites sp.1, Hypoxylonites sp.2 e Monoporisporites sp.2) e por patógenos (Multicellites sp.9 - Figura 3O, Lacrimasporonites cf. L. buerglii - Figura $3 \mathrm{~F}$ e Hypoxylonites lineatus - Figura 2Q). Isto confirma as interpretações de SANTOS (2009) para este intervalo, quanto à presença de mata fechada em condições climáticas mais frias.

\section{CONCLUSÕES}

A identificação e quantificação de fungos fósseis nem sempre é uma tarefa fácil, visto que estão preservados apenas conídios, esporos e hifas fragmentadas. Os fungos fósseis não apresentam estruturas germinativas, o que dificulta associá-los à ecologia dos fungos atuais.

O presente trabalho mostra a diversidade desta paleobiomicota desenvolvida em bacias orgânicas e preservada em turfeiras, que permitiu efetuar interpretações pioneiras de cunho paleoambiental, paleoecológico e paleoclimático, além de realizar comparações preliminares com espécimes atuais. A análise da paleomicota e a sua comparação com os resultados palinológicos (esporos e grãos de pólen) permitiram as seguintes conclusões:

- A maior diversidade de esporos encontrada foi de Hyphomycetes, que produzem conídios por reprodução assexuada;

- A paleomicobiota sugere desenvolvimento e preservação em ambiente redutor, com farta disponibilidade de matéria orgânica em decomposição;

- A dominância é de fungos de hábitos saprófitos, seguidos pelos de hábitos patogênicos, hábitos diversos, hábitos indeterminados, parasitas de vegetais, habitantes de solos, coprófitos, predadores gerais e parasitas de animais;

- Os intervalos são diferenciados pela quantidade em concentração de cada grupo e pela diversidade de espécies. O Intervalo III é o mais rico em diversidade e quantidade, enquanto o Intervalo II caracteriza-se por possuir a menor quantidade e diversidade de fungos.

- No intervalo I, dominam fungos saprófitos relacionados à decomposição de vegetação morta, como folhas de Cyperaceae (entre 11.240 cal. anos AP e 10.560 anos AP - idade interpolada), sugestivo da existência de corpos de água, com abundância de plantas herbáceas, arbustos e madeiras mortas, em condições climáticas quentes e úmidas. Entre as características distintivas deste intervalo estão: 1) abundância de fungos parasitas de vegetais, especialmente aqueles que habitam substratos lenhosos e mostram a ocorrência de vegetação arbórea; 2) fungos parasitas de animais são praticamente ausentes, 3) patógenos de vegetais são pouco representativos, 4) coprófitos estão muito bem representados, especialmente no topo do intervalo, sugestivo da presença de animais vertebrados.

- No intervalo II, os fungos saprófitos ocorrem em menores quantidades em relação aos intervalos I e III, mas mantêm-se como grupo dominante. Os fungos parasitas de animais são os mais bem representados. Patógenos de vegetais vivos também estão bem representados, como Anatolinites sp.1 (patógeno foliar), o que é sugestivo da existência de vegetação arbórea. No início e final do intervalo II, espécies como Inapertisporites sp.3 (fungos de solo) podem ser associadas a raízes de gramíneas (Poaceae). Trata-se de um dos micorrízicos que indicam a existência de vegetação rasteira e matas próximo às turfeiras;

- No intervalo III, a partir de 550 anos AP (idade interpolada), os fungos saprófitos dominam este intervalo. Em relação aos outros intervalos, verificam-se as maiores quantidades de fungos predadores, habitantes de solos, patógenos de vegetais, coprófitos e saprófitos. Esses últimos ocorrem em horizontes de turfa, especialmente hêmica, sugerindo a relação direta destes fungos decompositores com as plantas formadoras da turfa. Parasitas de vegetais estão presentes, mas são menos representativos que no intervalo I. 
- A atividade micobiótica de fungos patogênicos de vegetais pode ter ocorrido por influência de temperaturas mais frias em áreas de mata, no intervalo II, entre 740 cal. anos AP e 550 anos AP e no intervalo III, a 300 anos AP;

- Coprófitos, como Monoporisporites sp.6, que possuem registros em esterco de animais herbívoros, encontram-se próximo ao topo do intervalo III entre as idades 310 anos AP (interpolada) e 300 anos AP, possivelmente associada à atividade antrópica no médio vale do rio Paraíba do Sul. Essa conclusão é corroborada pela presença de fungos de hábitos diversos, como Monoporisporites sp.3, que vive em solos e serrapilheiras, e também em estercos;

- O estudo de palinomorfos de fungos fósseis poderá ainda resgatar a história sobre a relação dos patógenos com determinadas plantas em diferentes condições climáticas.

\section{AGRADECIMENTOS}

Os autores agradecem ao Projeto FAPESP 05/51034-6 Evolução da Floresta Atlântica no Sul-Sudeste do Brasil: abordagem integrada sedimentológica-micropaleontológica, que propiciou o suporte financeiro e equipamento para o desenvolvimento deste trabalho; aos revisores e editores da revista, pelas excelentes sugestões que permitiram aprimorar o presente artigo. O primeiro autor agradece à CAPES pela Bolsa Mestrado PROSUP.

\section{REFERÊNCIAS BIBLIOGRÁFICAS}

ALEXOPOULOS, C.J.; MINS, C.W.; BLACKWELL, M. 1996. Introductory Mycology. John Wiley and Sons, Inc., New York, 4th ed., 868 p.

ALIAS, S.A.; JONES, E.B.G. 2000. Colonization of mangrove wood by marine fungi at Kuala Selangor mangrove stand. Fungal Diversity, 5: 9-21.

ASTITI, N.P.A.; SUPRAPTA, D.N. 2012. Antifungal activity of teak (Tectona grandis 1.f) leaf extract against Arthrinium phaeospermum (Corda) M.B. Ellis, the cause of wood decay on Albizia falcataria (1.) fosberg. Journal of ISSAAS, 18(1): 62-69.

BAHRAMI, A.K.; PES, A.M.O.; ROMERO, G.; UEHARA-PRADO, M. 2002. Mortalidade de formigas por fungos Ascomycetes em um gradiente campinarana-platô, em uma área de terra firme da Amazônia Central. In: E. Venticinque \& J. Zuanon (ed.) Ecologia da Floresta Amazônica - Projeto 169. Dinâmica Biológica de Fragmentos Florestais. PDBFF - Instituto Nacional de pesquisa da Amazônia -INPA. p. 67- 68.

BARBOSA, F.F.; GERIS, R.; GUSMÃO, L.F.P. 2009. First record of Phialomyces macrosporus Misra \& Talbot. (conidial fungi) for Brazil. In: CONGRESSO NACIONAL DE BOTÂNICA, 60, Feira de Santana, BA, Boletim de Resumos, p. 1207.

BLAAUW, M.; CHRISTEN, J.A. 2011. Flexible paleoclimate age-depth models using an autoregressive gamma process. Bayesian Analysis, 6(3): 457-474.

CARVALHO, M.A. 1996. Estudo paleoecológico e paleoclimático, com base em palinologia, aplicado em sedimentos pleistocênicos e pliocênicos da bacia da foz do Amazonas. Universidade Federal do Rio de Janeiro, Rio de Janeiro, Dissertação de Mestrado, 146 p.

CASADO, F.C. 2009. Relação estratigráfica e ambiental neoquaternária entre a calha aluvial do Rio Paraíba do Sul e os depósitos de turfa associados entre os Municípios de São José dos Campos e Taubaté, SP. Centro de Pós-Graduação e Pesquisa Curso de Mestrado em Análise Geoambiental, Universidade Guarulhos, Guarulhos, Dissertação de Mestrado, $84 \mathrm{p}$.

CEDEÑO, L.; CARRERO, C.; QUINTERO, K.; PINO, H.; ESPINOZA, W. 2004. Cylindrocarpon destructans var. destructans and Neonectria discophora var. rubi associated with black foot rot on blackberry (Rubus glaucus Benth.) in Mérida, Venezuela. Interciencia, 29(8): 455-460.

COLINVAUX, P.; DE OLIVEIRA, P.E.; PATIÑO, J.E.M. 1999. Amazon Pollen Manual and Atlas: Manual e Atlas Palinológico da Amazônia. Harwood Academic Publishers, Amsterdam, $332 \mathrm{p}$.

CROUS, P.W.; GROENEWALD, J.Z. 2013. A phylogenetic re-evaluation of Arthrinium. IMA Fungus, 4(1): 133-154. 
CROUS，P.W.; SHIVAS， R.G.; QUAEDVLIEG, W.; VAN DER BANK, M.; ZHANG,Y.; SUMMERELL,B.A.;GUARRO,J.;WINGIELD, M.J.; WOOD, A.R.; ALFENAS, A.C.; BRAUN, U.; CANO-LIRA, J.F.; GARCÍA, D.; MARIN-FELIX, Y.; ALVARADO, P.; ANDRADE, J.P.; ARMENGOL, J.; ASSEFA, A.; DEN BREEŸEN, A.; CAMELE, I.; CHEEWANGKOON, R.; DE SOUZA, J.T.; DUONG, T.A.; ESTEVERA VENTÓS, F.; FOURNIER, J.; FRISULLO, S.; GARCÍAJIMÉNEZ, J.; GARDIE NNET, A.; GENÉ, J.; HERNÁNDEZ-RESTREPO, M.; HIROOKA, Y.; HOSPENTHAL, D.R.; KING, A.; LECHAT, C.; LOMBARD, L.; MANG, S.M.; MARBACH, P.A.S.; MARINCOWITZ, S.; MARIN-FELIX, Y.; MONTAÑO-MATA, N.J.; MORENO, G.; PEREZ C.A.; SIERRA, A.M.P.; ROBERTSON, J.L.;ROUX, J. ; RUBIO, E.; SCHUMACHER, R.K.; STCHIGEL, A.M.; SUTTON, D.A.; TAN, Y.P.; THOMPSON, E.H.; VAN DER LINDE, E.; WALKER, A.K.; WALKER, D.M.; WICKES, B.L.; WONG, P.T.W.; GROENEWALD, J.Z. 2014. Fungal Planet description sheets: 214-280. Persoonia, 32: 184-306.

CRUZ, A.C.R.; GUSMÃO, L.F.P. 2009. Fungos conidiais na Caatinga: espécies lignícolas. Acta Botanica Brasilica, 23(4): 1133-1144.

DAVEY, M.L.; TSUNEDA, A.; CURRAH, R.S. 2008. Evidence that the gemmae of Papulaspora sepedonioides are neotenous perithecia in the Melanosporales. Mycologia, 100(4): 626-635.

DIANESE， J.C.; CÂMARA， M.P.S. 1994. Pseudocercospora aspidospermatis - a new combination for Bactrodesmiella aspidospermatis. Sydowia, 46(2): 225-232.

EDIGER, V.S. 1981. Fossil fungal and algal bodies from Thrace Basin, Turkey. Palaeontographica, Abt. B, 179: 87-102.

ELSIK, W.C. 1968. Palynology of a Paleocene Rockdale lignite, Milam County, Texas. I. Morphology and taxonomy. Pollen et Spores, 10: 263-314.

ELSIK, W.C. 1971. Microbiological degradation of sporopollenin. In: J. Brooks, P.R. Grant, M. Muir, P. von Gijzel, G. Shaw (ed.) Sporopollenin. New York, Academic Press, p. 480-511.
ELSIK, W.C. 1976a. Fossil fungal spores. In: D.J. Weber \& W.H. Hess (ed.) The fungal spore: form and function. Second International Fungal Spore Symposium, Brigham Young University, 1974. The Fungal spore. New York, John Wiley \& Sons, Inc., p. 849-862.

ELSIK, W.C. 1976b. Microscopic fungal remains and Cenozoic palynostratigraphy. Geoscience and Man, 15: 115-120.

ELSIK, W.C.; BAESEMANN, C.B.; GRAHAM, A.K.; HOPKINS, W.S.; JANSONIUS, J.; JARZEN, D.M.; NORRIS, G.; PETERSON, E.T.; SRIVASTAVA, S.K.; SWEET, A.R.; TRAVERSE, A. 1983. Annotated glossary of fungal palynomorphs. A short course presented under the auspices of The American Association of Stratigraphic Palynologists. A.A.S.P.Contributions Series, 11, 35 p.

ESHET, Y.; RAMPINO, M.R.; VISSCHER, H. 1995. Fungal event and palynological record of ecological crisis and recovery across the PermianTriassic boundary. Geology, 23: 967-970.

FERREIRA, E.P.; CARVALHO, M.A.; VIVIERS, M.C. 2005. Palinologia (Fungos) da Formação Calumbi, Paleoceno da Bacia de Sergipe, Brasil. Arquivos do Museu Nacional, 63(3): 395-410.

FREITAS, A.G.; CARVALHO, M.A. 2011. Esporos de fungos holocênicos de testemunho da Lagoa da Ferradura (Armação do Búzios, Rio de Janeiro, Brasil). Revista Brasileira de Paleontologia, 14(2): 179-188.

FREITAS, A.G; CARRIÓN, J.S.; JIMÉNEZ, S.F.; PEDROZA, I.; CAROMANO, C.F.; CASCÓN, L.M.; BIANCHINI, G.F.; SILVA, S.F.S.M.; GHETTI, N.C.; OLIVEIRA, C.A. 2015. Manejo y cultivo de plantas en sierras húmedas del NE de Brasil ca. 670-530 BP: evidencias palinológicas del yacimiento Evaristo I. Journal Sagvntvm, 47: 203-231.

FURTADO, M.V. 2011. Micobiota associada a folhas de bananeira em Cabo Verde. Instituto Superior de Agronomia da Universidade Técnica de Lisboa, Lisboa, Dissertação de Mestrado, $60 \mathrm{p}$.

GARCIA, M.J. 1994. Palinologia de Turfeiras Quaternárias do Médio Vale do Rio Paraíba 
do Sul, Estado de São Paulo. Instituto de Geociências, Universidade de São Paulo, São Paulo, Tese de Doutorado, 3 vols., 354 p.

GARCIA, M.J. 1997. Palinologias de turfeiras quaternárias do Médio Vale do Rio Paraíba do Sul, SP, Brasil. Parte I: Fungos, Algas, Briófitas e Pteridófitas. Revista Universidade Guarulhos, Geociências, II (Número Especial): 148-165.

GARCIA, M.J.; DE OLIVEIRA, P.E.; SIQUEIRA, E.; FERNANDES, R.S. 2004. A Holocene vegetacional and climatic record from the Atlantic rainforest belt of coastal State of São Paulo, SE Brazil. Review of Palaeobotany and Palynology, 131: 181-199.

GELORINI, V.; VERBEKEN, A.; VAN GEEL, B.; COCQUYT, C.; VERSCHUREN, D. 2011. Modern non-pollen palynomorphs from East African lake sediments. Review of Palaeobotany and Palynology, 164(3-4): 143-173.

GRANDI, R.A.P.; SILVA, T.V.2003.Hyphomycetes sobre folhas em decomposição de Caesalpinia echinata Lam.: ocorrências novas para o Brasil. Revista Brasileira de Botânica, 26(4): 489-493.

GRIMM, E.C. 1987. CONISS: a Fortran 77 program for stratigrafically constrained cluster analysis by the method of the incremental sum of squares. Computer \& Geosciences, 13(1): 13-35.

GRUYTER, J.; VAN KESTEREN, H.A.; NOORDELOOS, M.E. ; PATERNOTTE, S.J.; VEENBAAS-RIJKS, J.W. 1992. The association of Humicola fuscoatra with corky root symptoms in wilted glasshouse tomatoes. Netherlands Journal of Plant Pathology, 98(4): 257-260.

HANDE, D.V.; SURADKAR K.P.; KADU, S.R. 2014. Diversity of Arthrinium from Melghat Forest, Amravati (MS) India. International Journal of Life Sciences, Special Issue A2: 99-101.

HASUI, Y.; PONÇANO, W.L.; BISTRICHI, C.A.; STEIN, D.P.; GALVÃO, C.A.F.; PAIVA FILHO, A.; ALMEIDA, M.A.; CARNEIRO, C.D.R.; SOBREIRO NETO, A. 1978. Geologia da Região Administrativa 3 (Vale do
Paraíba) e parte da Região Administrativa 2 (Litoral). Instituto de Pesquisas Tecnológicas do Estado de São Paulo, São Paulo.

HERRERA, T.; ULLOA, M. 1990. El reino de los hongos: micología básica y aplicada. Fondo de Cultura Económica, Unam, México, $500 \mathrm{p}$.

HOGG, A.G; HUA, Q.; BLACKWELL, P.G.; NIU, M.; BUCK, C.E.; GUILDERSON T.P.; HEATON, T.J.; PALMER, J.G.; REIMER P.J.; REIMER R.W.; TURNEY, C.S.M.; ZIMMERMAN, S.R.H. 2013. SHCal13 Southern Hemisphere calibration, 0-50,000 years cal BP. Radiocarbon, 55(4): 18891903.

JANSONIUS, J.; KALGUTKAR, R.M. 2000. Redescription of some fossil fungal spores. Palynology, 24: 37-47.

JARZEN, D.M.; ELSIK, W.C. 1986. Fungal palynomorphs recovered from recent river deposits, Luangwa Valley, Zambia. Palynology, 10: 35-60.

KALGUTKAR, R.M. 1997. Fossil fungi from the lower Tertiary Iceberg Bay Formation Eureka Sound Group, Axel Heiberg Island, North West Territories, Canada. Review of Palaeobotany and Palynology, 97: 197-226.

KALGUTKAR, R.M.; JANSONIUS，J. 2000. Synopsis of fossil fungal spores, Mycelia and fructifications. AAPS Contributions Series, $39,429 \mathrm{p}$.

KALGUTKAR, R.M.; SIGLER, L. 1995. Some fossil form-taxa from the Maastrichtian and Palaeogene ages. Mycological Research, 99: 513-522.

KAR, R.; MANDAOKAR, B.D.; KAR, R.K. 2010. Fungal taxa from the Miocene sediments of Mizoram, northeast India. Review of Palaeobotany and Palynology, 158(3-4): 240-249.

KÖPPEN, W. 1948. Climatología: con un estudio de los climas de la Tierra. Fondo de cultura econômica, México, 478 p.

KUBÁTOVÁ, A. 2006. Chaetomium in the Czech Republic and notes to three new records. Czech Mycology, 58 (3-4): 155-171. 
KUMAR, S.; SINGH R.; SAINI D.C.; KAMAL. 2012. A new species of Corynespora from Terai forest of northeastern Uttar Pradesh, India. Mycosphere, 3(4): 410-412.

KUTORGA，E; IRŠÉNAITÉ，R; IZNOVA，T; KASPARAVIČIUS, J.; MARKOVSKAJA, S.; MOTIEJUNAITE; J. 2003. A diversidade de espécies e composição das comunidades de fungos em uma floresta de pinheiros escoceses afetados pela grande colônia de corvos-marinhos. Acta Mycologica, 48(2): 173-188.

LEAL, M.G.; LORSCHEITTER, M.L. 2006. Pólen, esporos e demais palinomorfos de sedimentos holocênicos de uma floresta paludosa, Encosta Inferior do Nordeste, Rio Grande do Sul, Brasil. Iheringia, Série Botânica, 61(1-2): 13-47.

LORSCHEITTER, M.L. 1984. Palinologia de sedimentos quaternários do cone do Rio Grande, Brasil. Universidade Federal do Rio Grande do Sul, Porto Alegre, Tese de Doutoramento, $247 \mathrm{p}$.

MARQUES, A. 1990. Evolução tectonosedimentar e perspectivas exploratórias da Bacia de Taubaté, São Paulo Taubaté, Brasil. Boletim de Geociências da Petrobrás, 4(3): 253-262.

MARTIN, L.; FLEXOR, J.M.; SUGUIO, K. 1995. Vibrotestemunhador leve: construção, utilização e potencialidades. São Paulo. Revista do Instituto Geológico, 16(1/2): 59-66.

MEDEANIC, S.; GARCIA, M.J.; STEVAUX, J.C. 2004. A importância dos palinomorfos de fungos e de algas nas reconstruções paleoambientais por meio de estudos em sedimentos do Alto Rio Paraná, Taquaruçu, MS, Brasil. Revista da Universidade de Guarulhos, Geociências, 9(6): 19-40.

MONTANHEIRO, T.J. (coord.) 2009. Projeto Paraíba do Sul: potencialidade de areia. $1^{\mathrm{a}}$ ed., digital, São Paulo, IG, vol.1. 73 p.

MUNGAY, P.G.; CHUKEATIROTE, E.; NJOGU, J.G.; HYDE K.D. 2012. Studies of coprophilous ascomycetes in Kenya. Podospora species from wildlife dung. Mycosphere, 3(6): 978-995.
NEVES, P.C.P. 1998. Palinologia de sedimentos quaternários no Estado do Rio Grande do Sul, Brasil: Guaíba e Capão do Leão. Instituto de Geociências, Universidade Federal do Rio Grande do Sul, Porto Alegre, Tese de Doutorado, $513 \mathrm{p}$.

NEVES, P.C.P.; BAUERMANN, S.G. 2003. Catálogo palinológico de coberturas quaternárias no Estado Rio Grande do Sul (Guaíba e Capão do Leão), Brasil. Descrições Taxonômicas - Parte I: fungos, algas, palinomorfos e outros fragmentos de invertebrados. Botânica, 53: 121-149.

PALS, J.P.; VAN GEEL, B.; DELFOS, A. 1980. Paleoecological studies in the Klokkeweel bog near Hoogkarspel (prov. of Noord Holland). Review of Palaeobotany and Palynology, 30: 371-418

PEIXOTO JÚNIOR, R.F. 2011. Desenvolvimento e caracterização de marcadores microssatélites para Puccinia melanocephala, agente causador da ferrugem marrom em canade-açúcar. Centro de Energia Nuclear na Agricultura, Universidade de São Paulo, Piracicaba, Dissertação de Mestrado, 66 p.

PIROZYNSKI, K.A. 1976a. Fossil fungi. Annual Review of Phytopathology, 14: 237-246.

PIROZYNSKI, K.A. 1976b. Fungal spores in the fossil record. Biological Memoirs, 1: 104120.

PIROZYNSKI, K.A. 1976c. The role of fungal spores in stratigrafic palynology: analysis of fungal spores as taxonomic, morphologic and ontogenetic entities. Geoscience and Man, 15: $145-146$.

PIROZYNSKI, K.A.; JARZEN, D.M.; CARTER, A.; DAY, R.G. 1988. Palynology and mycology of organic clay balls accompanying mastodon bones - New Brunswick, Canada. Grana, 27: 123-139.

POPOV, P.A. 1967. Microskopicheskie griby kak obiekt palinologicheskich issledovanni. (Microscopic fungi as an object for Palynological study). Mikologia I fitologia. Moscow, Ed. Nauka, v.1, p. 158-163.

RAJA, H.A.; SHEARER, C.A. 2006. Jahnula species from North and Central America, 
including three new species. Mycologia, 98(2): 319-332.

RAMANUJAM, C.G.K.; RAO, K.P. 1978. Fungal spores from the Neogene strata of Kerala in South India. In: D.C. Bharadwaj et al. (ed.) Proceedings of the 4th International Palynological Conference, 1976-1977, Lucknow, v.1, p. 291-304.

RAMANUJAM, C.G.K.; SRISAILAM, K. 1980. Fossil fungal spores from the Neogene beds around Cannanore in Kerala state. The Botanique, 9: 119-133.

RAMBELLI, A. 2011. Some Dematiaceous Hyphomycetes from Mediterranean maquis litters. Flora Mediterranea, 21: 5-204.

RÉVAY, Á. 1985. Dematiaceous Hyphomycetes inhabiting Forest debris in Hungary I. Stüdia Botanica Hungarica (Antea: Fragmenta Botanica), 18: 65-71.

SANTOS, R.A. 2009. História paleoambiental neopleistocena-holocena do Médio Vale do Rio Paraíba do Sul, Estado de São Paulo, com base na análise da palinoflora. Centro de PósGraduação e Pesquisa Curso de Mestrado em Análise Geoambiental, Universidade Guarulhos, Guarulhos, Dissertação de Mestrado, 100 p.

SHEFFY, M.V.; DILCHER, D.L. 1971. Morphology and taxonomy of fungal spores. Palaeontographica, Abt. B, 133: 34-51.

SILVA, R.S. 2015. Considerações paleoambientais, com base em fungos quaternários, de turfas de Eugênio de Melo, Médio Vale do Rio Paraíba do Sul, SP, Brasil. Centro de Pós-Graduação e Pesquisa Curso de Mestrado em Análise Geoambiental, Universidade Guarulhos, Guarulhos, Dissertação de Mestrado, 194 p.

SILVEIRA, V.D. 1981. Micologia. Ed. Interamericana, Rio de Janeiro, $4^{\mathrm{a}}$ edição. $332 \mathrm{p}$.

SONG, C.C.;HUANG, F. 2002. On the classification of fossil fungi. Acta Paleontológica Sinica, 41(4): 471-477.

STOCKMARR, J. 1972. Tablets with spores used in absolute pollen analysis. Pollen et Spores, 13: 615-621.
TAYLOR, T.N.; OSBORN, J.M. 1996. The importance of fungi in shaping the paleoecosystem. Review of Palaeobotany and Palynology, 90: 249-262.

TEIXEIRA-SANTOS, R.; RICARDO, E.; GUERREIRO S.G.; COSTA-DEOLIVEIRA, S.; RODRIGUES A.G.; PINAVAZ, C. 2015. News Insights Regarding Yeast Survival following Exposure to Liposomal Amphotericin B. Antimicrobial Agents Chemotherapy, 59(10): 6181-6187.

THAUNG, M.M. 2009. A new species of Uromyces (Pucciniales) on Trichosanthes (Cucurbitaceae) from Burma. Australasian Mycological Society Inc., 28: 43-44.

ULFIG, K. 1994. The occurrence of keratinolytic fungi in the polluted environment of the Labedy District in Gliwice. Roczniki Panstwowego Zakladu Higieny, 45(4): 337346.

URURAHY J.C.C.; COLLARES， J.E.R.; SANTOS, M.M.; BARRETO, R.A.A. 1983. Vegetação. In: Projeto Radambrasil, Rio de Janeiro/Vitória, vol. 32, p. 553-623.

VALE, F.X.R.; ZAMBOLIM, L.; COSTA, L.C.; LIBERATO, J.R.; DIAS, A.P.S. 2004. Influência do clima no desenvolvimento de doenças de plantas. In:F.X.R. Vale, W.C. Jesus Jurnior, L. Zambolim (ed.) Epidemiologia aplicada ao manejo de doenças de plantas. Belo Horizonte, Perfil, p. 47-87.

VAN GEEL, B. 1978. A palaeoecological study of Holocene peatbog sections in Germany and the Netherlands. Review of Palaeobotany and Palynology, 25: 1-120.

VAN GEEL, B.; APTROOT, A. 2006. Fossil ascomycetes in Quaternary Deposits. Journal Nova Hedwigia, 82(3-4): 313-329.

VAN GEEL, B.; BONCKE, S.J.P.; DEE, H. 1980. A palaeoecological study of an Upper LateGlacial and Holocene Sequence from "De Borchet" The Netherlands. Review of Palaeobotany and Palynology, 31(3/4): 367-448.

VAN GEEL, B.; GUTHRIE, R.D.; ALTMANN, J.G.; BROEKENS, P.; BULL, I.D.; GILL, F.L.; JANSEN, B.; NIEMAN, A.M.; GRAVENDEEL, B. 2011a. Mycological 
evidence of coprophagy from the feces of an Alaskan Late Glacial mammoth. Quaternary Science Reviews, 30(17-18): 2289-2303.

VAN GEEL, B.; GELORINI, V.; LYARUU, A.; APTROOT, A.; RUCINA, R.; MARCHANT, R.; DAMSTÉ, J.S.S.;VERSCHUREN, D. 2011b. Diversity and ecology of tropical African fungal spores from a 25,000-year palaeoenvironmental record in southeastern Kenya. Review of Palaeobotany and Palynology, 164: 174-190.
VERDADE, F.; HUNGRIA, L.S. 1966. Estudo genético da bacia orgânica do Vale do Paraíba. Bragantia, 25(16): 189-202.

WEBSTER, J. 1952. Spore projection in the hyphomycete Nigrospora sphaerica. New Phytologist, 51: 229-235.

WOLF, F.A. 1967a. Fungus spores in East African lake sediments, V. Mycologia, 59: 392-404.

WOLF, F.A. 1967b. Fungus spores in East African lake sediments, VII. Bulletin of the Torrey Botanical Club, 94: 480-486.

\section{Endereço dos autores:}

Raimundo Souza Silva e Rosana Saraiva Fernandes - Universidade Guarulhos, Praça Tereza Cristina, $\mathrm{n}^{\circ}$ 88, Centro, CEP: 07023-070, Guarulhos, SP, Brasil.E-mails: raispiritist@yahoo.com, rosana.rs@ gmail.com

Maria Judite Garcia, Rudney de Almeida Santos, Paulo Eduardo De Oliveira, Paulo César Fonseca Giannini, Mary Elizabeth C. Bernardes-de-Oliveira e Vanda Brito de Medeiros - Departamento de Geologia Sedimentar e Ambiental, Programa de Pós-Graduação em Geoquímica e Geotectônica, Instituto de Geociências, Universidade de São Paulo, Rua do Lago, 562, Cidade Universitária, CEP: 05508-080, São Paulo, SP, Brasil.E-mails: mjudite@usp.br; rudney@usp.br; paulo.deoliveira@usp.br; pcgianni@ usp.br; maryeliz@usp.br; vanda.medeiros@usp.br

Carlos Alberto Bistrichi - Praça Carauari, 75, apto. 61, CEP: 02130-000, São Paulo, SP, Brasil. E-mail: cabistrichi@uol.com.br

Marco Felipe Raczka - Biology Department, Florida Institute of Technology, 150 W, University Blvd Melbourne, Florida, 32901, USA. E-mail: mraczka2009@my.fit.edu

Artigo submetido em 1 de dezembro de 2015, aceito em 8 de janeiro de 2016. 